\title{
Disappearing money illusion
}

\section{Tom Engsted and Thomas Q. Pedersen}

CREATES Research Paper 2018-24 


\title{
Disappearing money illusion*
}

\author{
Tom Engsted ${ }^{\dagger} \quad$ Thomas Q. Pedersen ${ }^{\ddagger}$
}

August 2018

\begin{abstract}
In long-term US stock market data the price-dividend ratio strongly predicts future inflation with a positive slope coefficient up to the mid 1970s. Thereafter, the predictability turns negative. We argue that this phenomenon reflects money illusion that disappears during the 1970s. We develop a consumption-based asset pricing model with recursive preferences and either money illusion or inflation nonneutrality that can explain the predictive patterns. The model is also consistent with a structural shift around the mid 1970s in the real interest rate - inflation relationship, thus supporting the hypothesis of disappearing money illusion at that time.
\end{abstract}

JEL Classification: C22, E31, E44, G12, G17

Keywords: Modigliani-Cohn money illusion, predictive regressions, long-run risk, inflation non-neutrality

*An earlier version of the paper was circulated under the title "The predictive power of dividend yields for future inflation: Money illusion or rational causes?". Part of this research was done while Tom Engsted was visiting UC Berkeley and The Federal Reserve Bank of San Francisco in the fall of 2015. The help and hospitality of the people at those places are gratefully acknowledged. A special thanks to Michael Jansson and Kevin Lansing. The paper has benefitted from comments from participants at a seminar at the research department of the San Francisco Fed and the SGF Conference 2017. The authors also acknowledge support from The Danish Council of Independent Research (DFF 4003-00022) and CREATES - Center for Research in Econometric Analysis of Time Series (DNRF78), funded by the Danish National Research Foundation.

†Department of Economics and Business Economics, Aarhus University, Fuglesangs Allé 4, DK-8210 Aarhus V, Denmark. E-mail: tengsted@econ.au.dk.

${ }^{\ddagger}$ Department of Economics and Business Economics, Aarhus University, Fuglesangs Allé 4, DK-8210 Aarhus V, Denmark. E-mail: tqpedersen@econ.au.dk. 


\section{Introduction}

Since Fisher (1928) it has been widely recognized that people may suffer from money illusion in the sense of confusing nominal with real variables. They mistakenly consider an increase in the nominal value due to a general increase in the price level to be an increase in the real purchasing power. In financial markets money illusion leads to mispricing and in the finance literature the most prominent model to explain such mispricing is the Modigliani and Cohn (1979) hypothesis according to which investors discount real cash flows with nominal discount rates. This causes stock markets to be undervalued in times of high inflation and overvalued in times of low inflation. At the time of writing (end of the 1970s) Modigliani and Cohn's hypothesis provided an explanation for the depressed stock prices at the time.

In the finance literature several studies have reported empirical evidence consistent with the Modigliani-Cohn hypothesis, e.g. Campbell and Vuolteenaho (2004), Cohen, Polk, and Vuolteenaho (2005), and Brunnermeier and Julliard (2008). ${ }^{1}$ The main empirical implication of the hypothesis is that the price-dividend ratio is negatively related to expected inflation. In this literature expected inflation is typically modeled as a smoothed backward-looking function of past inflation. As emphasized by Campbell and Vuolteenaho (2004), the Modigliani-Cohn hypothesis is radical because it assumes that only stock market investors suffer from money illusion; bond market investors do not display such irrationality. Of course this leaves the question as to why there should be this difference between the two types of investors. As an alternative to the Modigliani-Cohn hypothesis, Basak and Yan (2010) develop an economic model in which both stock and bond market investors suffer from money illusion. All investors share the same stochastic discount factor and they behave rationally (optimize and have rational expectations) except that the stochastic discount factor features money illusion. Despite these differences to the Modigliani-Cohn model, Basak and Yan's model shares the main implication with the Modigliani-Cohn hypothesis, i.e. a negative relation between the price-dividend ratio and expected inflation.

In the current paper we approach the money illusion hypothesis from a new angle. We first document that in long-term US data up to the mid 1970s, the price-dividend ratio is strongly and positively related to future inflation (see Figure 1 and Table 1 below). An interesting implication of this kind of predictability is that real stock returns are

\footnotetext{
${ }^{1}$ The effects of money illusion on financial markets have received growing attention in recent years. A non-exhaustive list includes Asness (2000, 2003), Sharpe (2002), Ritter and Warr (2002), Chen, Lung and Wang (2009), Lee (2010), Bekaert and Engstrom (2010), Wei (2010), and Acker and Duck (2013).
} 
more predictable by the price-dividend ratio than nominal stock returns. Similarly, real dividend growth is less predictable than nominal dividend growth. These implications are confirmed in the data. The positive inflation predictability by the price-dividend ratio is consistent with the presence of money illusion although at first sight it seems to be at odds with the prevailing view that stock prices and expected inflation are negatively related.

Next, we develop an economic model that explains the positive relation between the price-dividend ratio and future inflation. We follow Basak and Yan (2010) and assume that both stock and bond market investors suffer from money illusion. In their model consumption and dividend growth are independently and identically distributed (iid) and investors have time-separable power utility. However, this model cannot explain the positive stock price - inflation relationship. In the spirit of Bansal and Yaron (2004), we extend Basak and Yan's model to feature recursive preferences and a small persistent component in consumption and dividend growth. This extension is crucial for generating the positive relation between the price-dividend ratio and future inflation that we see in the data up to the mid 1970s.

We calibrate the model with reasonable values of preference parameters and show that it generates time-series of inflation, dividend growth, consumption growth, and the price-dividend ratio with moments that match the moments of actual data. In particular, the model is able to match the positive relationship between the price-dividend ratio and future inflation. By contrast, with time-separable power utility - as in Basak and Yan (2010) - the model generates a counterfactual negative relationship between the pricedividend ratio and future inflation. As expected, when we calibrate the model to display no money illusion, there is no relationship between these two variables.

Since the 1970s the strong and positive stock price - inflation relationship has disappeared. Over the last 40 years the price-dividend ratio has been negatively related to future inflation. Thus, a structural shift appears to have happened in the mid 1970s. We document this shift and discuss economic explanations for it. We conjecture that the high-inflation period of the late 1960s and early 1970s made people more aware of the consequences of inflation, and in both the general public and the academic community (cf. Modigliani and Cohn, 1979) this led to a renewed interest in the phenomenon of money illusion which contributed to its disappearence. Thus, the disapperance of money illusion resembles the disappearence of financial market anomalies when they are discovered, e.g. the well-known 'size anomaly' discovered by Banz (1981) which seems to have disappeared or at least significantly reduced since its discovery, cf. Schwert (2003). 
The increased awareness of inflation and its consequences for the real economy during the 1970s was furthermore triggered by the breakdown of the Phillips curve and the outbreak of 'stagflation' (cf. Bruno and Sachs, 1985). There is evidence that from the 1970s expected inflation and expected consumption growth become directly connected and that this 'inflation non-neutrality' effect can explain the negative relation between the price-dividend ratio and future inflation that characterizes the period since the mid 1970s. In our economic model calibrated to a period starting in the mid 1970s, when we replace money illusion with a direct negative relationship between expected consumption growth and expected inflation - as in e.g. Bansal and Shaliastovich (2013) - the pricedividend ratio significantly predicts future inflation with a negative sign, in accordance with the data. By contrast, this version of the model cannot explain the data up to the mid 1970s.

Thus, compared to the existing literature, our analysis offers the following new explanation of the stock price - inflation relationship in the US over the period 1871-2016: Up to the mid 1970s financial market investors suffered from money illusion, resulting in a positive relation between stock prices and expected inflation. After the high-inflation period of the 1970s, money illusion disappeared. Instead, since the mid 1970s expected inflation has had a direct negative impact on expected economic growth which has resulted in a negative relationship between stock prices and expected inflation.

As further evidence in support of our model, we analyze the implications of the model for the term structure of real interest rates. In general, the literature has found that real interest rates are negatively related to expected inflation (Ang, Bekaert, and Wei, 2008; Bansal and Shaliastovich, 2013). Our model is consistent with this finding. In addition, in the model money illusion implies that the short-term real interest rate predicts future inflation with a negative coefficient. This relationship is confirmed in US data up to the mid $1970 \mathrm{~s}$, but is significantly weakened thereafter. Thus, interestingly, there seems to be a structural shift in the real interest rate - inflation relationship around the mid 1970s which can be explained by the disappearence of money illusion, consistent with our explanation for the structural shift in the stock price - inflation relationship.

The rest of the paper is organized as follows. Section 2 presents the empirical evidence of the relationship between the price-dividend ratio and future inflation. It also documents the structural shift in the relationship in the mid 1970s. In Section 3 we develop an economic model featuring money illusion that explains the positive relation between the price-dividend ratio and future inflation up to the mid 1970s. This includes a simulation study where we calibrate the model to match US data. In Section 4 we ex- 
tend the model to also feature 'inflation non-neutrality' and show that this is a potential explanation for the negative relation between the price-dividend ratio and future inflation prevailing since the mid 1970s. Section 5 studies the implications of our model for the term structure of real interest rates and Section 6 concludes. The Appendix contains a description of the bootstrap procedure used to compute p-values in the predictability regressions, and it gives the detailed derivations of the central equations of the economic model.

\section{The price-dividend ratio and future inflation}

Empirical studies of money illusion in the stock market typically consider the relation between the price-dividend ratio and a constructed measure of expected inflation. For example, Campbell and Vuolteenaho (2004) use an exponentially declining moving average of past inflation as their measure of expected inflation and regress the price-dividend ratio onto that measure. Assuming that actual inflation is positively correlated with expected inflation, and in the spirit of Fama (1975), we instead consider predictive regressions of future actual inflation on the price-dividend ratio. Table 1 presents regression results based on

$$
\pi_{t, t+k}=\alpha_{\pi, k}+\beta_{\pi, k} p d_{t}+\varepsilon_{\pi, t+k}
$$

where $p d_{t}$ is the log price-dividend ratio and $\pi_{t, t+k}=\sum_{j=0}^{k-1} \pi_{t+1+j}$ denotes the sum of one-period log inflation from period $t$ to $t+k$. As emphasized by Cochrane (2008), $k$ needs to be at least 15 to 20 years to get the power gains of long-horizon regressions, so we let $k$ take the values $1,5,10,15$, and 20 years. With $\beta_{\pi, k} \neq 0$ expected inflation is time-varying as captured by the price-dividend ratio. For $k=1$ we compute $t$-statistics using Newey and West (1987) heteroskedasticity and autocorrelation robust standard errors, while for $k>1$ we use Hodrick (1992) standard errors, which for these types of regressions have better size properties in small samples, cf. Ang and Bekaert (2007). To account for potential small-sample bias that can arise due to the use of a highly persistent predictor variable such as the price-dividend ratio, we also report bootstrapped p-values $\left(P_{B}\right.$ in Table 1$)$ computed under the null hypothesis of no predictability (see Appendix 1 for details of the bootstrap procedure). We use Robert Shiller's annual US data, which cover the period 1871-2016. For the regressions in Table 1 we use S\&P stock prices and dividends as well as the Consumer Price Index to compute inflation and the price-dividend 
ratio. $^{2}$

For the full sample period (1871-2016) Table 1 shows that the price-dividend ratio predicts future inflation with a positive sign. This holds irrespective of the horizon, although the statistical evidence is strongest for large values of $k$. Figure 1 gives a graphical representation of inflation predictability by the price-dividend ratio. The figure shows the log price-dividend ratio (the solid line) and the subsequent 20-year log inflation rate (the dashed line). Inflation stops at 1996, the last year with a 20-year future inflation rate (from 1996 to 2016). As seen, there is a clear tendency that the two variables move together.

However, Figure 1 also indicates a structural shift in the relation between the pricedividend ratio and future inflation. Since the mid 1970s the price-dividend ratio appears to predict future inflation with a negative sign. To show that this structural shift holds across all horizons, Table 1 contains predictive regression results for the two sub-sample periods: 1871-1976 and 1977-2016. The early sub-sample is defined such that the last observation for $p d_{t}$ is in 1976, while inflation continues for an additional $k$ years to be consistent with the forecast regression (1). For the latter sub-sample we only consider horizons of 1 and 5 years due to a lower number of observations. In this sample period the first observation for $p d_{t}$ is 1977 and future inflation begins in 1978. Inflation thus overlaps to a certain degree across the two sub-sample periods, but importantly the data for the price-dividend ratio are distinctively different. ${ }^{3}$

In the early sub-sample the price-dividend ratio predicts future inflation with a positive sign and the statistical evidence is even stronger than for the full sample period. For example, $\beta_{\pi, k}$ is now also statistically different from zero for $k=1$ as evidenced by the bootstrapped p-value of 0.017 and the $R^{2}$ has more than doubled compared to the full sample period. However, for the late sub-sample the predictive coefficient, $\beta_{\pi, k}$, has changed sign, but the relation is still statistically significant for both $k=1$ and 5 . The price-dividend ratio thus significantly predicts future inflation with a positive sign up till the mid 1970s and with a negative sign thereafter.

In Table 1 and in our subsequent analyses we have set the break date between 1976 and 1977. In some sense this is an arbitrary choice but we emphasize that none of

\footnotetext{
${ }^{2}$ In unreported regressions we obtain similar results using data from the Center for Research in Security Prices (CRSP). We present our findings based on Robert Shiller's data since these cover a longer sample period compared to CRSP data. (Here and all subsequent places where we refer to unreported results, details are available upon request to the authors).

${ }^{3}$ Formal tests support a structural break in $\beta_{\pi, k}$ in 1976-1977. For example, for $k=5$ a Chow breakpoint test yields a Wald test statistic of 7.85 and a corresponding p-value of 0.005 .
} 
our results change qualitatively by changing this date one or two years to either side. The basic question is: when did people realize that the economy had moved to a new inflation regime? During the 1960s inflation rose, but - Friedman (1968) and Phelps (1968) notwithstanding - financial markets, policy makers, and the general public did not acknowledge the fundamental shift in the relation between inflation and the real economy until the breakdown of the Phillips curve and the outbreak of 'stagflation' during 19731975 (cf. Bruno and Sachs, 1985). In 1976 Milton Friedman received the Nobel prize and in his Nobel lecture (Friedman, 1977) he discusses in detail this shift, emphasizing both the importance of expectations and the tendency to confuse nominal for real changes, i.e. money illusion. In relation to the new paradigm of inflation, Friedman writes (p. 469): "It restored the primacy of the distinction between real and nominal magnitudes". Thus, one can argue that 1976-1977 marks the end of the 'old view' and beginning of the 'new view' of inflation. The increased attention to the impact of inflation immediately led to analyses of inflation's impact on asset prices (e.g. Fama and Schwert, 1977; Modigliani and Cohn, 1979: Fama, 1981).

The empirical results in Table 1 raise a fundamental question. The existing literature on money illusion generally supports a negative relation between stock prices and expected inflation, both empirically (e.g. Campbell and Vuolteenaho, 2004) and theoretically (Basak and Yan, 2010). Does that then rule out money illusion as a potential explanation for the documented positive relation between the price-dividend ratio and actual future inflation up to the mid 1970s? Furthermore, what explains the negative relation between the price-dividend ratio and future inflation since the mid 1970s? In the remainder of the paper, we address these questions.

\subsection{The price-dividend ratio and future returns and dividend growth}

Before presenting a formal model of money illusion we will elaborate on the consequences of inflation predictability by the price-dividend ratio for our understanding of price movements in the stock market. The price-dividend ratio is often used as predictor for future stock returns and dividend growth. Campbell and Shiller (1988) provide theoretical support for using the price-dividend ratio as predictor through their log-linearized present 
value relation (the dynamic Gordon growth model):

$$
p d_{t}=E_{t} \sum_{j=0}^{\infty} \rho^{j}\left(\Delta d_{t+1+j}-r_{t+1+j}\right)+\frac{c}{1-\rho}
$$

$\Delta d_{t+1}$ is the first difference of log dividends, $r_{t}$ is log stock return, $\rho=e^{E(p d)} /(1+$ $\left.e^{E(p d)}\right)$, and $c$ is a linearization constant. $E_{t}$ is the expectations operator, conditional on information at time $t .^{4}$

Equation (2) holds for both nominal and real variables. If we define $r_{t+1+j}$ and $\Delta d_{t+1+j}$ in nominal terms and let $\pi_{t+1+j}$ denote log inflation from time $t+j$ to $t+1+j$, then we can write equation (2) as

$$
p d_{t}=E_{t} \sum_{j=0}^{\infty} \rho^{j}\left[\left(\Delta d_{t+1+j}-\pi_{t+1+j}\right)-\left(r_{t+1+j}-\pi_{t+1+j}\right)\right]+\frac{c}{1-\rho} .
$$

Thus, the price-dividend ratio reflects expected future returns and/or dividend growth either in nominal or in real terms. This just reflects the fact that the price-dividend ratio is independent of whether dividends and prices are measured in nominal or real terms. The rewrited Campbell-Shiller relation, equation (3), is a dynamic accounting identity that automatically links the current price-dividend ratio to future returns, dividend growth, and inflation.

If investors do not suffer from money illusion, a change in expected inflation $\left(\pi_{t+1+j}\right)$ will change expected nominal returns $\left(r_{t+1+j}\right)$ and nominal dividend growth $\left(\Delta d_{t+1+j}\right)$ one for one and leave $p d_{t}$ unaffected. However, if investors do suffer from money illusion, $p d_{t}$ will move with changes in $\pi_{t+1+j}$, and from (3) it is clear that if $p d_{t}$ has predictive power for future inflation then it will predict nominal and real returns and dividend growth differently. As seen from (3), depending on the sign of inflation predictability, real returns and/or dividend growth will be either more or less predictable than nominal returns and/or dividend growth. With positive inflation predictability we should expect real returns to be more predictable than nominal returns, and vice versa for dividend growth.

Table 2 shows the results from the following regressions over the sample period 1871-

\footnotetext{
${ }^{4}$ Equation (2) is derived based on a first-order Taylor expansion of the definition of the one-period return. Thus, there is a linearization error that makes (2) only hold approximately. Campbell and Shiller (1988) and Engsted, Pedersen, and Tanggaard (2012) show, however, that the approximation error is negligible.
} 


$$
\begin{aligned}
x_{t, t+k} & =\alpha_{n, k}+\beta_{n, k} p d_{t}+\varepsilon_{n, t+k}, \\
\left(x_{t, t+k}-\pi_{t, t+k}\right) & =\alpha_{r, k}+\beta_{r, k} p d_{t}+\varepsilon_{r, t+k},
\end{aligned}
$$

where $x_{t, t+k}$ is either $\sum_{j=0}^{k-1} r_{t+1+j}$ or $\sum_{j=0}^{k-1} \Delta d_{t+1+j}$, i.e. the sum from period $t$ to $t+k$ of one-period nominal log returns or one-period nominal log dividend growth. ${ }^{5}$ We use the same data and the same standard errors and bootstrap approach as in the case of inflation predictability (Table 1).

Evaluating return predictability in Table 2, we see that although the slope coefficient has the theoretically correct negative sign, cf. (2), nominal returns are statistically unpredictable by the price-dividend ratio even at a $10 \%$ significance level (except for $k=5$ ). The price-dividend ratio is, however, a strong predictor of future real returns. Taking small-sample bias into account (i.e. using the p-value $P_{B}$ ) we find evidence of real return predictability for $k>1$ at a $5 \%$ significance level and for $k=1$ at a $10 \%$ significance level.

The interesting implication of these findings is that if returns are truly unpredictable, positive inflation predictability will make real returns predictable, as evidenced by the significant $\widehat{\beta}_{r, k}$ values in Table 2 . Conversely, if returns are truly predictable, such inflation predictability may make nominal returns unpredictable, as evidenced by the insignificant $\widehat{\beta}_{n, k}$ values in Table 2. Similarly, we find that nominal dividend growth is significantly predictable with the theoretically correct positive sign, cf. (2), but only for $k=1$ is real dividend growth predictable. In fact, for $k>5$ the predictive coefficient turns negative. These results are consistent with positive inflation predictability over the period 18711976 as shown in Table 1. ${ }^{6}$ We believe that these differences between nominal and real return and dividend growth predictability due to inflation predictability are not generally acknowledged, although emphasized by Engsted and Pedersen (2010). Whether to interpret the empirical results as evidence of predictability or unpredictability of returns and dividend growth by the price-dividend ratio naturally hinges on the underlying economic

\footnotetext{
${ }^{5}$ According to (3) it should be future long-horizon discounted inflation, returns, and dividend growth (where the discount factor is $\rho$ ) that are related to $p d_{t}$. Since $\rho$ is only slightly less than one, in practice it makes no difference whether the variables are discounted or not, and hence we do not discount with $\rho$. We have done all regressions also using discounted values and none of the results change qualitatively.

${ }^{6}$ Unreported results show that for the period 1977-2016, nominal stock returns are more predictable by the price-dividend ratio than real returns (both with a negative sign), which is consistent with negative inflation predictability in this period (cf. Table 1). Also for dividend growth is the difference between real and nominal predictability consistent with negative inflation predictability, although dividend growth is virtually unpredictable in this period.
} 
model. In the next section we develop an economic model based on money illusion to explain the positive relation between the price-dividend ratio and future inflation.

\section{$3 \quad$ Is money illusion the explanation?}

To evaluate if money illusion can explain the positive relation between the price-dividend ratio and future inflation, we derive an economic model that explicitly allows investors to suffer from money illusion. The model is related to the long-run risk model of Bansal and Yaron (2004) based on Epstein and Zin (1989) and Weil (1989) recursive preferences. Our model is also related to the asset pricing model of Basak and Yan (2010) who consider the impact of money illusion but do so using time-separable power utility. Both analytically and through a simulation study, the model delivers important economic insights into money illusion as an explanation for the positive relation between the price-dividend ratio and future inflation.

As will become clear through the rest of the paper, existing models linking asset prices to inflation cannot explain the positive relation between stock prices and and future inflation over the period 1871-1976. This includes the model by Basak and Yan (2010) based on time-separable power utility and featuring money illusion, and the longrun risk model by Bansal and Shaliastovich (2013) featuring inflation non-neutrality. In contrast, the model developed in this paper is consistent with the empirical findings over the period 1871-1976.

\subsection{Economic model}

The representative agent is assumed to have Epstein and Zin (1989) and Weil (1989) recursive preferences,

$$
U_{t}=\left\{(1-\delta) C_{t}^{\frac{1-\gamma}{\theta}}+\delta\left(E_{t}\left[U_{t+1}^{1-\gamma}\right]\right)^{\frac{1}{\theta}}\right\}^{\frac{\theta}{1-\gamma}}, \quad \theta=\frac{1-\gamma}{1-\frac{1}{\psi}}
$$

where $C_{t}$ is real consumption at time $t, 0<\delta<1$ is the time discount factor, $\gamma \geq 0$ is the coefficient of relative risk aversion, and $\psi \geq 0$ is the intertemporal elasticity of substitution. In the special case where $\gamma=1 / \psi$, that is $\theta=1$, the above recursive preferences collapse to standard time-separable power utility. Note also that the sign of $\theta$ is determined by $\gamma$ and $\psi$. For example, $\theta$ will be negative if $\gamma>1$ and $\psi>1$, but 
positive if $\gamma>1$ and $\psi<1$. While there is general agreement that $\gamma>1$, the value of $\psi$ is subject to controversy. Hall (1988) and Beeler and Campbell (2012), among others, find evidence of $\psi<1$ while, for example, Attanasio and Weber (1993), Attanasio and Vissing-Jorgensen (2003), and Chen, Favilukas, and Ludvigson (2013) find $\psi$ to be above one. ${ }^{7}$

Maximizing the utility function subject to the budget constraint $W_{t+1}=\left(W_{t}-C_{t}\right) R_{c, t+1}$ yields the following Euler equation for asset $i$,

$$
E_{t}\left[\delta^{\theta}\left(\frac{C_{t+1}}{C_{t}}\right)^{-\frac{\theta}{\psi}} R_{c, t+1}^{-(1-\theta)} R_{i, t+1}\right]=1
$$

where $W_{t}$ is wealth, $R_{i, t}$ is the gross return on asset $i$, and $R_{c, t}$ is the gross return on a claim to aggregate consumption. This implies that the log stochastic discount factor is given as

$$
m_{t+1}=\theta \ln (\delta)-\frac{\theta}{\psi} \Delta c_{t+1}-(1-\theta) r_{c, t+1},
$$

where lowercase letters denote logs to the corresponding uppercase letters. If investors suffer from money illusion in the sense that they discount real cash flows with a nominal discount factor the log stochastic discount factor can be written as

$$
\widehat{m}_{t+1}=m_{t+1}-\lambda \pi_{t+1}
$$

where $0 \leq \lambda \leq 1$ determines the degree of money illusion. $\lambda=1$ implies perfect money illusion, while $\lambda=0$ implies no money illusion. This way of modeling the stochastic discount factor under (partial) money illusion follows Basak and Yan (2010) and implies that both stock and bond market investors fail to properly account for the effect of inflation. This contrasts with the traditional Modigliani and Cohn (1979) hypothesis, where only stock market investors suffer from money illusion. Thus, there is a different kind of incoherence involved in the two approaches to money illusion: in Modigliani-Cohn type of money illusion bond markets are rational but stock markets are not. In Basak and Yan's model, by contrast, both markets are rational in all aspects, except that investors use a distorted stochastic discount factor to discount real cash flows on all assets.

In Section 5 we study the effects of money illusion on the term structure of real interest

\footnotetext{
${ }^{7}$ Thimme (2017) provides a review of the empirical literature on the intertemporal elasticity of substitution and finds that the size of $\psi$ (including whether it is larger or smaller than 1) depends on, among others, the use of aggregate consumption data or microdata, the estimation technique, the underlying economic model, and the sample period.
} 
rates, but for now we focus on the stock market. We follow Bansal and Yaron (2004) and distinguish between the unobservable return on the claim to aggregate consumption, $R_{c, t+1}$, and the observable return on the dividend claim, $R_{m, t+1}$, i.e. the return on the market portfolio, and log-linearize these returns, cf. Campbell and Shiller (1988):

$$
\begin{aligned}
r_{c, t+1} & =k_{c, 0}+k_{c, 1} p c_{t+1}-p c_{t}+\Delta c_{t+1} \\
r_{m, t+1} & =k_{d, 0}+k_{d, 1} p d_{t+1}-p d_{t}+\Delta d_{t+1} .
\end{aligned}
$$

$p c_{t}$ is short-hand notation for the log price-consumption ratio and $p d_{t}$ is (as before) the $\log$ price-dividend ratio. $k_{i, 0}$ and $k_{i, 1}$ for $i=c, d$ are constants that are a function of the linearization point which typically is chosen to be the sample average of the ratio in question. ${ }^{8}$ More specifically, $k_{i, 1}$ is computed as $\exp (z) /[1+\exp (z)]$ and $k_{i, 0}$ as $-\ln \left(k_{i, 1}\right)-\left(1-k_{i, 1}\right) \ln \left(1 / k_{i, 1}-1\right)$, where $z$ denotes the linearization point for the pricedividend ratio and price-consumption ratio, respectively.

To close the model, we assume that consumption, dividends, and inflation have the following dynamics:

$$
\begin{aligned}
\Delta c_{t+1} & =\mu_{c}+x_{c, t}+\sigma_{c} \eta_{c, t+1}, \\
\Delta d_{t+1} & =\mu_{d}+\phi x_{c, t}+\sigma_{d} \eta_{d, t+1}, \\
\pi_{t+1} & =\mu_{\pi}+x_{\pi, t}+\sigma_{\pi} \eta_{\pi, t+1}, \\
x_{c, t+1} & =\beta_{1} x_{c, t}+\sigma_{x c} \varepsilon_{c, t+1}, \\
x_{\pi, t+1} & =\beta_{3} x_{\pi, t}+\sigma_{x \pi} \varepsilon_{\pi, t+1} .
\end{aligned}
$$

All shocks $\left(\eta_{i, t+1}, i=c, d, \pi ; \varepsilon_{i, t+1}, i=c, \pi\right)$ are mutually uncorrelated iid normally distributed with mean zero and variance one. Consumption growth, dividend growth, and inflation are all modeled as containing a small persistent predictable component $\left(x_{c, t}\right.$ and $x_{\pi, t}$, with $\beta_{1}>0$ and $\beta_{3}>0$ ). Note that dividend growth is driven in part by the persistent consumption growth component through the leverage parameter $\phi$. This feature of the model follows Bansal and Yaron (2004). Note also that although inflation will have real effects through money illusion, inflation will be 'neutral' by not directly affecting the real variables of the model. In Section 4 we extend equation (11) by the term $\beta_{2} x_{\pi, t}$ to allow for inflation non-neutrality.

We consider the simplest possible setup that will deliver insights into the relation

\footnotetext{
${ }^{8}$ Engsted et al. (2012) show that the upper bound for the mean approximation error is minimized by setting the linearization point equal to the unconditional mean of the ratio.
} 
between the price-dividend ratio and future inflation and, hence, we do not allow for time-varying volatility. Our aim is not to develop a model that can explain all features of the data, but to focus on the relation between the price-dividend ratio and inflation, similar to what Campbell and Vuolteenaho (2004) and Basak and Yan (2010) do. The model can, however, easily be extended to include time-varying volatility along the lines of Bansal and Yaron (2004). ${ }^{9}$

In solving the model we first conjecture that the log price-consumption ratio is a linear function of the state variables:

$$
p c_{t}=A_{0}+A_{1} x_{c, t}+A_{2} x_{\pi, t}
$$

With joint log-normality the Euler equation for the consumption claim (allowing for potential money illusion), can be written as

$$
\begin{aligned}
0 & =E_{t}\left[\theta \ln (\delta)-\frac{\theta}{\psi} \Delta c_{t+1}+\theta r_{c, t+1}-\lambda \pi_{t+1}\right] \\
& +\frac{1}{2} \operatorname{Var}_{t}\left[\theta \ln (\delta)-\frac{\theta}{\psi} \Delta c_{t+1}+\theta r_{c, t+1}-\lambda \pi_{t+1}\right] .
\end{aligned}
$$

Inserting the data-generating processes for the state variables (8)-(12), the log-linearized return relation (6), and the log price-consumption ratio (13), we verify the conjectured solution. See Appendix 2 for additional details as well as the expressions for $A_{0}, A_{1}$ and $A_{2}$ (in a generalized setting where we also allow for inflation non-neutrality, cf. Section $4)$.

Next, we conjecture that the log price-dividend ratio is also a linear function of the state variables:

$$
p d_{t}=B_{0}+B_{1} x_{c, t}+B_{2} x_{\pi, t} .
$$

Again, with joint log-normality the Euler equation for the dividend claim (allowing for

\footnotetext{
${ }^{9}$ The assumption of constant volatility implies constant risk premia, but extending the model to include time-varying volatility and hence time-varying risk premia does not change the relation between the price-dividend ratio and expected inflation shown later in (14) and (16). Furthermore, unreported simulation results show similar empirical relations between the price-dividend ratio and future inflation whether or not volatility is constant or time-varying.
} 
potential money illusion), can be written as

$$
\begin{aligned}
0 & =E_{t}\left[\theta \ln (\delta)-\frac{\theta}{\psi} \Delta c_{t+1}-(1-\theta) r_{c, t+1}+r_{m, t+1}-\lambda \pi_{t+1}\right] \\
& +\frac{1}{2} \operatorname{Var}_{t}\left[\theta \ln (\delta)-\frac{\theta}{\psi} \Delta c_{t+1}-(1-\theta) r_{c, t+1}+r_{m, t+1}-\lambda \pi_{t+1}\right] .
\end{aligned}
$$

Similar to the case with the price-consumption ratio we insert the data-generating processes for the state variables (8)-(12), the log-linearized return relations (6)-(7), the log priceconsumption ratio (13), and the log price-dividend ratio (14) to verify the conjectured solution. See Appendix 3 for additional details as well as the expression for $B_{0}$ (in a generalized setting where we also allow for inflation non-neutrality, cf. Section 4). The coefficients of interest in our case are $B_{1}$ and $B_{2}$ that are given as

$$
\begin{aligned}
& B_{1}=\frac{\phi-\frac{1}{\psi}}{1-k_{d, 1} \beta_{1}}, \\
& B_{2}=\frac{-\frac{\lambda}{\theta}}{1-k_{d, 1} \beta_{3}} .
\end{aligned}
$$

Regarding the sign of $B_{1}$ we first see that the denominator is positive (assuming a stationary process for expected consumption growth and a log-linearization constant below 1), while the sign of the numerator depends on the relative size of the leverage coefficient $\phi$ and the intertemporal elasticity of substitution $\psi ; B_{1}>0$ for high values of $\psi$ relative to $\phi$, and vice versa. In other words, for $\psi>1 / \phi$ higher expected growth leads investors to buy more stocks driving up the price-dividend ratio, i.e. the substitution effect dominates. In contrast, for $\psi<1 / \phi$ the wealth effect dominates such that the price-dividend ratio decreases when expected growth increases.

The link between the price-dividend ratio and expected inflation is determined by $B_{2}$. Again, we see that the denominator is positive (assuming a stationary process for expected inflation and a log-linearization constant below 1) such that our main focus should be on the numerator. Since $\lambda$ is positive, the sign of $B_{2}$ is determined by $\theta=(1-\gamma) /(1-1 / \psi)$. The empirical evidence of a positive relation between the pricedividend ratio and inflation documented in Table 1 can thus be explained by investors suffering from money illusion and having recursive preferences with the preference parameters $\psi$ and $\gamma$ simultaneously being either larger than one or smaller than one such that $\theta<0$ and, hence, $B_{2}>0$. In contrast, if either $\psi$ or $\gamma$ is above one and the other preference parameter is below one, then there will be a negative relation between the price-dividend ratio and expected inflation. Note that this negative relation will 
also arise if investors have time-separable power utility in which case $\theta=1$, which is consistent with the model of Basak and Yan (2010).

To gain some intuition for money illusion and its impact on stock prices it is instructive to consider the Euler equation (4) which can be written as:

$$
E_{t}\left\{\exp \left[(\theta-1) r_{c, t+1}+\theta \ln (\delta)+\frac{\gamma-1}{\psi-1} \Delta c_{t+1}-\lambda \pi_{t+1}+r_{i, t+1}\right]\right\}=1
$$

Note that in the special case of standard power utility $\left(\gamma=\frac{1}{\psi}\right)$ the first term in the brackets cancels out and the coefficient on consumption growth is $-\gamma$ instead of $\frac{\gamma-1}{\psi-1}$. If inflation is expected to increase at time $t+1$, then marginal utility for an investor suffering from money illusion will decrease at time $t+1$. Stated differently, the investor suffering from money illusion expects higher returns at time $t+1$ simply due to increases in inflation. As also argued by Basak and Yan (2010), a standard power utility investor responds to the decrease in marginal utility by transfering consumption from time $t+1$ to $t$ resulting in decreasing asset prices at time $t$. Hence, there is a negative relation between asset prices and expected inflation. With recursive preferences the investor's consumption decision depends on both the degree of relative risk aversion and the intertemporal elasticity of substitution. For example, with $\gamma>1$ and a dominating substitution effect $(\psi>1)$, increases in expected inflation leads the investor to transfer consumption from time $t$ to $t+1$ resulting in increasing asset prices at time $t$. In other words, the investor seeks to take advantage of the perceived higher expected returns by reducing consumption and increasing savings at time $t$, causing an upward pressure on asset prices.

\subsection{Simulation study}

To explore the implications from the economic model in terms of inflation predictability by the price-dividend ratio, we calibrate the model at the annual frequency such that it matches the mean, standard deviation and persistence of dividend growth, consumption growth, and inflation, respectively, over the sample period 1871-1976. We focus on this sub-sample period due to the observed structural break in the mid 1970s and because the positive relation between the price-dividend ratio and future inflation in this period seems to contrast with existing evidence (e.g. Campbell and Vuolteenaho, 2004). (In Section 4 we compare our results with those of Campbell and Vuolteenaho). Data are from Robert Shiller's website as in Section 2. Note that consumption is only available 
from 1890.

To provide some inspiration for the data-generating parameters related to the latent variables of the model, we estimate equations (11) and (12) using survey data for expected inflation and expected consumption growth (proxied by expected GDP growth). We consider data both from the Livingston Survey, which is given on a semi-annual basis since 1951, and from the Survey of Professional Forecasters, which is given on a quarterly basis since 1968. In both cases we make use of one-year ahead forecasts. Table 3 contains the results. Although the survey data cover a much smaller sample period, we use the estimated coefficients and regression standard errors (both converted to annual frequency) to guide us in our choice of data-generating parameter values. ${ }^{10}$

The data-generating parameters and the results from inflation predictability regressions with horizons matching those in Table 1 are given in Table 4, while Table 5 contains the corresponding descriptive statistics. The persistence parameters $\beta_{1}$ and $\beta_{3}$ are set equal to 0.50 and 0.90, respectively. Bansal and Yaron (2004) choose the value 0.979 for $\beta_{1}$ in their calibration at a monthly frequency ( $\beta_{3}$ does not appear in their model). Our expected consumption growth series display much less persistence. This is due to our use of annual instead of monthly data, and because we calibrate the model to the period 1871-1976 where realized consumption growth (and dividend growth, inflation, and the price-dividend ratio) display relatively little persistence as seen from Table 5. For $\phi$ we follow Bansal and Yaron and set it equal to 3. In our main scenario we set $\gamma=2$ and $\psi=2$. The reported numbers are averages across 10,000 simulations each of length $105+k$, which matches the length of the sample period 1871-1976 plus the forecast horizon consistent with the empirical analysis in Table $1 .^{11}$

The first set of results in Panel A of Table 4 is for the case with no money illusion $(\lambda=$

\footnotetext{
${ }^{10}$ Bansal and Shaliastovich (2013) use data from the Survey of Professional Forecasters to estimate equations similar to (11) and (12). In Section 4 we compare our results to those of Bansal and Shaliastovich.

${ }^{11}$ At this point it will be relevant to address the critique of Epstein, Farhi, and Strzalecki (2014). They criticize the long-run risk literature based on Epstein-Zin-Weil preferences for not paying enough attention to temporal resolution of risk, which is a function of the preference parameters and the datagenerating process for consumption. They ask the question: "What fraction of your consumption stream would you give up in order for all risk to be resolved next month?" and call this fraction the timing premium. Based on the consumption process and preference parameters used by Bansal and Yaron (2004), Epstein et al. compute the timing premium to be of the order 25-30 percent, which they find to be unrealistically high. Compared to Bansal and Yaron, we work with a much lower value of relative risk aversion, a less persistent consumption process, and constant volatility, all of which reduce the size of the timing premium. With constant volatility and $\gamma=\psi=2$, as in our main scenario, Figure 1 in Epstein et al. (2014) indicates a timing premium in the order of 5-10 percent. Due to a less persistent consumption process the timing premium will be even lower in our case. Hence, Epstein et al.'s critique is not a concern in our case.
} 
$0, \psi=2, \gamma=2)$. As expected from (16) there is in this case no inflation predictability from the price-dividend ratio; the slope coefficients and t-statistics are virtually zero. If we allow for money illusion but assume investors have time-separable power utility $(\lambda=1, \psi=0.5, \gamma=2$, cf. Panel B in Table 4) we would expect to find a negative relation between the price-dividend ratio and inflation, cf. (16) and Basak and Yan (2010). This is exactly what we find in the simulation study. The slope coefficients are negative and strongly significant for all horizons. Note, however, that this is in direct contrast to the empirical results for the early sub-sample in Table 1, where the slope coefficients are positive. If we allow for money illusion and recursive preferences $(\lambda=1$, $\psi=2, \gamma=2$, cf. Panel $\mathrm{C}$ in Table 4) the simulation results line up much better with the empirical findings. The slope coefficients are significantly positive for all horizons.

To ensure that our results under money illusion and recursive preferences do not come about due to unrealistic simulated data, Table 5 compares the mean, standard deviation, and persistence of actual dividend growth, consumption growth, inflation, and the price-dividend ratio over the period 1871-1976 to the simulated series. Overall we see a good match between the actual and simulated data, except for the standard deviation of the price-dividend ratio and the persistence of inflation which are a bit too low in the simulated data.

In our main scenario we set $\gamma=\psi=2$, but the inflation predictability results do not critically hinge on these specific values of the preference parameters. However, high relative risk aversion will reduce the degree of inflation predictability; the absolute value of $\theta=(1-\gamma) /(1-1 / \psi)$ will increase and hence the effect of money illusion will decrease, cf. (16). Likewise, values of $\psi$ closer to 1 and only partial money illusion, $0<\lambda<1$, will also reduce predictability. These implications are all supported by unreported simulation results.

The main result in this section is that in a model featuring money illusion and recursive preferences, and with reasonable preference parameters, we are able to match the positive relation between the price-dividend ratio and future inflation up till the mid 1970s. In the next section we investigate an alternative model and look specifically at the most recent period 1977-2016. 


\section{$4 \quad$ What about inflation non-neutrality?}

Given that the existing literature on money illusion generally supports a negative relation between stock prices and expected inflation, it is interesting to observe the results for the sample period 1977-2016 in Table 1 which are consistent with this literature. The natural question is whether money illusion explains both the positive relation between stock prices and future inflation up till the mid 1970s and the negative relation since then? This would be possible if, for example, there was a structural shift in the intertemporal elasticity of substitution at that time such that it went from being above 1 to below 1. However, what would explain such a structural shift exactly at that point in time? Although there is empirical evidence that the intertemporal elasticity of substitution varies over time, cf. Thimme (2017), the existing literature does not suggest a structural shift in $\psi$ in the mid 1970s.

We can also interpret our findings such that money illusion emerged in the mid 1970s if we are willing to assume that $\gamma>1$ and $\psi<1$. The negative relation between the pricedividend ratio and inflation documented in Table 1 for the period 1977-2016 would then be consistent with the existing literature. However, that would require an alternative explanation for the positive relation between the price-dividend ratio and inflation up till the mid 1970s. In this section we explore inflation non-neutrality as a potential alternative explanation.

Following Bansal and Shaliastovich (2013), we extend the economic model to allow for inflation non-neutrality by replacing (11) with

$$
x_{c, t+1}=\beta_{1} x_{c, t}+\beta_{2} x_{\pi, t}+\sigma_{x c} \varepsilon_{c, t+1}
$$

which creates a link between real consumption growth (and hence the stochastic discount factor) and expected inflation, thereby giving a rational alternative to money illusion for explaining the relation between stock prices and inflation. In solving the model with (17) instead of (11) we maintain the conjecture that the log price-dividend ratio is a linear function of the state variables, cf. (14). $B_{1}$ remains unchanged while $B_{2}$ now reflects the effect of inflation non-neutrality (see Appendix 3 for details):

$$
B_{2}=\frac{k_{d, 1} B_{1} \beta_{2}-\frac{\lambda}{\theta}}{1-k_{d, 1} \beta_{3}}
$$

With no money illusion, $\lambda=0$, but inflation non-neutrality, $\beta_{2} \neq 0$, it is possible to 
obtain a positive relation between the price-dividend ratio and expected inflation. This is the case if $B_{1}$ and $\beta_{2}$ are of the same sign. Recall that the sign of $B_{1}$ depends on the size of $\psi$ relative to $\phi$ (i.e. whether the substitution effect or the wealth effect dominates), while the sign of $\beta_{2}$ is more unclear and ultimately an empirical matter. In a long-run risk setup Bansal and Shaliastovich (2013) use (17) to study the effect of inflation nonneutrality on bond return predictability and violations of the uncovered interest rate parity in currency markets. Using data from the Survey of Professional Forecasters from 1969 to 2010, they find evidence that $\beta_{2}<0$ which is in line with the common perception that if inflation has a direct effect on the real economy it should be with a negative sign.

If $\beta_{2}<0$, the wealth effect needs to dominate (i.e. $\psi<1 / \phi$ ) in order for the pricedividend ratio to be positively related to expected inflation. In this case an increase in expected consumption growth as a consequence of a decrease in expected inflation $\left(\beta_{2}<0\right)$ leads to a smaller increase in expected dividend growth (through $\left.\phi\right)$ than in expected returns (through $\psi$ ), and thereby drive down the price-dividend ratio. In contrast, if $\beta_{2}<0$ and the substitution effect dominates (i.e. $\psi>1 / \phi$ ) the price-dividend ratio and expected inflation are negatively related, consistent with the empirical results for the period since the mid 1970s.

To further study the presence of inflation non-neutrality and a potential break in $\beta_{2}$ in the mid 1970s, we estimate (17) for the period up till 1976 and over the period 19772016 using data from both the Survey of Professional Forecasters and the Livingston Survey. The results are given in Table 3, Panel C. We cannot reject that $\beta_{2}=0$ in the early sub-sample period, which suggests that inflation non-neutrality cannot explain the positive relation between stock prices and future inflation up till the mid 1970s. Likewise, we cannot reject that $\beta_{2}=0$ over the period 1977-2016. However, in estimating their asset pricing model over the period 1969-2010, Bansal and Shaliastovich (2013) conclude that $\beta_{2}$ is significantly negative. And, despite our formal non-rejection of $\beta_{2}=0$, the results in Table 3 indicate a potential change of sign of $\beta_{2}$ such that it turns negative in the mid 1970s. The breakpoint tests reported in the notes to Table 3 do in fact support a structural break in $\beta_{2}$ in the mid 1970s for both the Livingston Survey and the Survey of Professional Forecasters. Similar to the inflation predictability results (Table 1) it is interesting to note that the shift in $\beta_{2}$ comes after a period of high inflation and increased attention to the impact of inflation on asset prices and economic growth (cf. section 2). The negative $\beta_{2}$ combined with a dominating substitution effect, such that $B_{1}$ is positive (which is the case for the parameters used in the simulation study in Section 3.2), implies a negative relation between stock prices and expected inflation 
in accordance with the empirical results for the sample period 1977-2016. The results in Table 3, Panel C, thus suggest that inflation non-neutrality can explain the negative relation between stock prices and inflation since the mid 1970s.

To explore further if inflation non-neutrality can explain the empirical findings in the sample period 1977-2016 we conduct a simulation study similar to the case with money illusion, where we calibrate the model at the annual frequency. Again we use the results from Table 3 (converted to annual frequency) to guide our choice of datagenerating parameter values for the expected consumption and expected inflation series. The data-generating parameters and the results from inflation predictability regressions with horizons matching those in Table 1 are given in Table 6 . We maintain the same preference parameters as in the case of money illusion, i.e. $\gamma=2$ and $\psi=2$. Table 6 shows that $\beta_{2}<0$ does generate the theoretically correct negative slope coefficient (given $\psi>1 / \phi$, which is the case when $\psi=2$ and $\phi=3$ ) when predicting future inflation by the price-dividend ratio.

In their empirical analysis spanning the period 1927-2002, Campbell and Vuolteenaho (2004) find evidence of a negative relation between the price-dividend ratio and expected inflation constructed as an exponentially declining moving average of past inflation. To analyze if our economic model is consistent with Campbell and Vuolteenaho's empirical results we simulate time series of length 75 (corresponding to the period 1927-2002) with the first 50 observations (1927-1976) based on the data-generating parameters in Table 4 and the last 25 observations (1977-2002) based on the data-generating parameters in Table 6. Using the combined time series, unreported results reveal a negative relation between the price-dividend ratio and expected inflation constructed using an adaptive expectations formation scheme as in Campbell and Vuolteenaho. Our findings are thus not in contrast to those by Campbell and Vuolteenaho; the difference just reflects that Campbell and Vulteenaho use a sample period that includes a structural break in the relation between the price-dividend ratio and inflation.

Overall, the above results suggest that $\beta_{2}$ turned negative in the mid 1970s and that this is a potential explanation for the negative relation we have observed between stock prices and inflation since that time, cf. Table 1 . If we are willing to claim that $\beta_{2}<0$ from the mid 1970s based on the results in Table 3 (although also acknowledging that Bansal and Shaliastovich, 2013, find evidence that $\beta_{2}$ is significantly negative over a period starting in 1969) one could also argue that $\beta_{2}>0$ up till the mid 1970s. That is, high expected inflation would lead to high expected economic growth, as in a standard Phillips curve. A positive $\beta_{2}$ can yield a positive relation between stock prices and 
expected inflation when $\psi=2$ and $\phi=3$, cf. (18). To further distinguish between the two competing explanations for the positive relation between stock prices and future inflation in the period 1871-1976, we turn to the term structure of real interest rates in the next section.

\section{What about the term structure of real interest rates?}

Following Basak and Yan (2010), we specify the stochastic discount factor as in (5) which implies that both stock and bond market investors suffer from money illusion, in contrast to the traditional Modigliani and Cohn (1979) hypothesis where only stock market investors are not able to properly account for the effect of inflation. Given that our model implies that also bond market investors suffer from money illusion we now consider the impact of money illusion on the term structure of real interest rates. We allow for both money illusion and inflation non-neutrality. Apart from the presence of money illusion the model is closely related to the term structure model by Bansal and Shaliastovich (2013) who also formulate their model in a consumption-based long-run risk setup.

Given joint log-normality and money illusion, the Euler equation for real zero coupon bonds is given as

$$
p_{t}^{(n)}=E_{t}\left(p_{t+1}^{(n-1)}+\widehat{m}_{t+1}\right)+\frac{1}{2} \operatorname{Var}_{t}\left(p_{t+1}^{(n-1)}+\widehat{m}_{t+1}\right)
$$

where $\widehat{m}_{t+1}$ is given by (5) and $p_{t}^{(n)}$ denotes the log price of a real zero coupon bond at time $t$ with $n$ periods to maturity. Using the same approach as in the case of stocks, we conjecture that the real bond price is a linear function of the state variables,

$$
p_{t}^{(n)}=D_{0}^{(n)}+D_{1}^{(n)} x_{c, t}+D_{2}^{(n)} x_{\pi, t},
$$

where the coefficients are now a function of maturity. Next, we insert (20) into the Euler equation (19) along with the data-generating processes for the state variables (8)-(10), (12), (17), the log-linearized return relation (6), and the log price-consumption ratio (13) to verify the conjectured solution (see Appendix 4 for additional details). Since the real interest rate is given as $r_{t}^{(n)}=-p_{t}^{(n)} / n$, we get the following model-implied term structure 
of real interest rates:

$$
\begin{aligned}
r_{t}^{(n)} & =\frac{1}{n}\left(-D_{0}^{(n)}+\frac{1}{\psi} \cdot \frac{1-\beta_{1}^{n}}{1-\beta_{1}} x_{c, t}\right. \\
& \left.+\left[\frac{\lambda}{\theta} \cdot \frac{1-\beta_{3}^{n}}{1-\beta_{3}}-\beta_{2}\left(D_{1}^{(n-1)}+\beta_{3} D_{1}^{(n-2)}+\beta_{3}^{2} D_{1}^{(n-3)}+\ldots+\beta_{3}^{n-2} D_{1}^{(1)}\right)\right] x_{\pi, t}\right) .
\end{aligned}
$$

For $n=1$ this simplifies to

$$
r_{t}^{(1)}=-D_{0}^{(1)}+\frac{1}{\psi} x_{c, t}+\frac{\lambda}{\theta} x_{\pi, t}
$$

since $D_{1}^{(n-j)}$ is not defined for $n=1$.

As we saw in Section 3, to explain the positive relation between stock prices and inflation with money illusion it must hold that $\theta<0$, i.e. $\gamma$ and $\psi$ need to be simultaneously either larger or smaller than one. In (21) with $\theta<0$, money illusion implies a negative relation between the short term real interest rate and expected inflation. This relation also holds for $n>1$ since $\left(1-\beta_{3}^{n}\right) /\left(1-\beta_{3}\right)>0$. Thus, in periods with high expected inflation real interest rates are low, which drives up stock prices consistent with our findings in Section 3. It is also consistent with the general finding in the empirical literature of a negative relation between short term real interest rates and expected inflation, e.g. Ang et al. (2008). Also, replacing the price-dividend ratio as predictor for future inflation in Table 1 with the 1-year real interest rate from Robert Shiller's data, Table 7 shows a strong negative relation across all horizons consistent with the economic model under money illusion. Interestingly, since the mid 1970s the relation between real interest rates and inflation appears less strong. For $k=1$ there is a strong negative relation up till the mid 1970s $\left(P_{B}=0.000, R^{2}=0.091\right)$ while since the mid 1970s the relation is insignificant $\left(P_{B}=0.218, R^{2}=0.018\right)$. These findings are consistent with money illusion being present until the mid 1970s and then disappearing. ${ }^{12}$

As seen from (21), inflation non-neutrality has no effect on the short term real interest rate, but for $n>1$ a negative $\beta_{2}$ implies a negative relation between real interest rates and expected inflation since $D_{1}^{(i)}<0$ for all $i$. This is consistent with Bansal and Shaliastovich (2013). The strong negative relation between the short term real interest rate and inflation up till the mid 1970s can thus not be explained by inflation non-neutrality, which provides additional support to money illusion as the explanation for the empirical findings. Likewise, the potential presence of inflation non-neutrality since the mid 1970s,

\footnotetext{
${ }^{12}$ Consistent with the case of inflation predictability by the price-dividend ratio, we obtain similar results using CRSP data and the 3-month Treasury Bill rate as proxy for the short-term interest rate.
} 
as argued in Section 4, should have no impact on the short term real interest rate, cf. (21), which again is consistent with the empirical evidence in Table 7. As mentioned in Section 4 , a positive $\beta_{2}$ could in theory explain the positive relation between stock prices and inflation in the period 1871-1976, but again, $\beta_{2}$ has no impact on the short term real interest rate and this explanation would thus be inconsistent with the empirical findings in Table 7.

\section{Concluding remarks}

In this paper we have argued that a fundamental shift in the relationship between stock prices and inflation happened during the 1970s. Up to the mid 1970s financial markets suffered from money illusion, but the high and increasing inflation of the late 1960s and early 1970s made investors more aware of the impact of inflation and, thus, money illusion disappeared. The main motivation for our analysis is the new finding that up to the mid 1970s the price-dividend ratio strongly and positively predicts future inflation, whereas over the last 40 years the price-dividend ratio predicts future inflation with a negative coefficient.

We have argued that the increased awareness of inflation and its consequences during the late 1960s and first half of the 1970s explains both the disappearance of money illusion and the appearance of inflation non-neutrality, i.e. the direct negative effect of inflation expectations on real economic growth. In the financial economics literature this direct effect is often modeled as in equation (17) with $\beta_{2}<0$ (e.g. Bansal and Shaliastovich, 2013). Our analysis is consistent with such a direct inflation non-neutrality effect kicking in after the structural shift in the mid 1970s. Our analysis then also points to an explanation for the depressed stock prices at the late 1970s that is fundamentally different from the explanation given by Modigliani and Cohn (1979) and Campbell and Vuolteenaho (2004). They argue that the low stock prices were caused by high expected inflation in combination with money illusion in the stock market (but not in the bond market). Our model implies that by the end of the 1970s money illusion had vanished; instead, high expected inflation led to low expected economic growth and, consequently, to low stock prices.

Furthermore, our money illusion explanation for the stock price - inflation relationship up to the mid 1970s differs fundamentally from the traditional Modigliani-Cohn explanation. In our model both stock and bond markets suffer from money illusion and investors 
have recursive preferences with low risk aversion and high elasticity of intertemporal subsitution. In combination with small but persistent components in economic growth, this model generates the positive relation between the price-dividend ratio and future inflation that we see in the data up to the mid 1970s. The Modigliani-Cohn model cannot explain this positive relationship. 


\section{Appendices}

\section{Appendix 1. The bootstrap procedure}

The general scheme in the bootstrap procedure to test the null hypothesis of no predictability, while accounting for potential small-sample bias, is as follows:

1. Use OLS to estimate

$$
y_{t, t+k}=\alpha_{k}+\beta_{k} p d_{t}+\varepsilon_{t+k}
$$

where $y_{t, t+k}=\left\{\pi_{t, t+k}, r_{t, t+k}, r_{t, t+k}-\pi_{t, t+k},\right\}$ to obtain an estimate of $\beta_{k}$, denoted $\widehat{\beta}_{k}$, for $k=\{1,5,10,15,20\}$.

2. Use OLS to estimate

$$
\begin{aligned}
y_{t+1} & =\alpha+\beta p d_{t}+\varepsilon_{t+1}, \\
p d_{t+1} & =\varpi+\eta p d_{t}+\omega_{t+1},
\end{aligned}
$$

where $y_{t+1}=\left\{\pi_{t+1}, r_{t+1}, r_{t+1}-\pi_{t+1},\right\}$, i.e. we here consider one-period inflation, nominal returns, and real returns. This yields the following relevant estimates: $\widehat{\alpha}$, $\widehat{\varpi}, \widehat{\eta}$, and $\widehat{\Omega}$, where $\Omega$ is the covariance matrix of the residuals:

$$
\Omega=\left[\begin{array}{cc}
\sigma_{\varepsilon}^{2} & \sigma_{\varepsilon \omega} \\
\sigma_{\varepsilon \omega} & \sigma_{\omega}^{2}
\end{array}\right] .
$$

3. Generate $T$ random numbers of $\left(\varepsilon_{t+1}, \omega_{t+1}\right)$ from a multivariate normal distribution with covariance matrix $\widehat{\Omega}$. We denote these simulated error terms $\left(\varepsilon_{t+1}^{*}, \omega_{t+1}^{*}\right)$.

4. Generate a random initial value of $p d_{t}$ :

$$
p d_{1}^{*} \sim \mathcal{N}\left(\overline{p d}, \widehat{\sigma}_{p d}^{2}\right)
$$

where $\overline{p d}$ and $\widehat{\sigma}_{p d}^{2}$ denote the sample average and the variance, respectively, of the price-dividend ratio.

5. Use $\widehat{\varpi}$ and $\widehat{\eta}$ together with the generated values of $\omega_{t+1}$ and the initial value in steps 3 and 4 to obtain $T$ observations of $p d_{t}$ :

$$
\widehat{\varpi}+\widehat{\eta} p d_{t}^{*}+\omega_{t+1}^{*} \rightarrow p d_{t+1}^{*}
$$


6. Use $\widehat{\alpha}$ together with the generated values of $\varepsilon_{t+1}$ to obtain $T$ observations of $y_{t}$ under the null hypothesis $\beta=0$ :

$$
\widehat{\alpha}+\varepsilon_{t+1}^{*} \rightarrow y_{t+1}^{*}
$$

7. Construct multi-period inflation/returns $y_{t, t+k}^{*}=\sum_{i=0}^{k-1} y_{t+1+i}^{*}$ for $k=\{1,5,10,15,20\}$ using the one-period series. The following steps are carried out for all relevant values of $k$.

8. Use OLS to estimate

$$
y_{t, t+k}^{*}=\alpha_{k}+\beta_{k} p d_{t}^{*}+\varepsilon_{t+k}^{*},
$$

and denote the estimated slope coefficient $\widetilde{\beta}_{k}^{(1)}$.

9. Repeat steps $3-8 M=10,000$ times to obtain $\widetilde{\beta}_{k}^{(1)}, \widetilde{\beta}_{k}^{(2)}, \ldots, \widetilde{\beta}_{k}^{(M)}$.

10. Compute the upper one-sided p-value under the null hypothesis as

$$
P\left(\widetilde{\beta}_{k}>\widehat{\beta}_{k}\right)=\frac{1}{M} \sum_{i=1}^{M} I\left[\widetilde{\beta}_{k}^{(i)}>\widehat{\beta}_{k}\right]
$$

where $I[\cdot]$ is an indicator function. For the lower one-sided p-value, the inequality signs are reversed.

11. Compute the bias as

$$
\operatorname{bias}\left(\widehat{\beta}_{k}\right)=\frac{1}{M} \sum_{i=1}^{M} \widetilde{\beta}_{k}^{(i)} \text {. }
$$

We have evaluated the robustness of the results in a number of ways. First, we have done the analysis using residual-based bootstrapping in step 2 as an alternative to parametric bootstrapping. Second, we have adjusted $\widehat{\eta}$ for bias before generating data in step 5. Finally, given a fairly persistent inflation process we have $i$ ) generated data such that $\varepsilon_{t+1}^{*}$ follows an $\operatorname{AR}(1)$ process, $\left.i i\right)$ made use of a block bootstrap, and $i i i$ ) included lagged inflation as a predictor variable both in the predictive regression and in the bootstrap. None of these modifications of the bootstrap procedure outlined above changes the qualitative conclusions in the empirical analysis. 


\section{Appendix 2. Solving for the price-consumption ratio}

With joint log-normality the Euler equation for the consumption claim (allowing for potential money illusion) can be written as:

$E_{t}\left[\theta \ln (\delta)-\frac{\theta}{\psi} \Delta c_{t+1}+\theta r_{c, t+1}-\lambda \pi_{t+1}\right]+\frac{1}{2} \operatorname{Var}_{t}\left[\theta \ln (\delta)-\frac{\theta}{\psi} \Delta c_{t+1}+\theta r_{c, t+1}-\lambda \pi_{t+1}\right]=0$

Inserting the data-generating processes for the state variables (8)-(10), (12), (17), the log-linearized return relation (6), and the conjectured log-price consumption ratio (13), the conditional mean is given by:

$$
\begin{aligned}
& E_{t}\left[\theta \ln (\delta)-\frac{\theta}{\psi} \Delta c_{t+1}+\theta r_{c, t+1}-\lambda \pi_{t+1}\right] \\
& =\theta \ln (\delta)-\frac{\theta}{\psi}\left(\mu_{c}+x_{c, t}\right)+\theta\left(k_{c, 0}+k_{c, 1}\left(A_{0}+A_{1}\left[\beta_{1} x_{c, t}+\beta_{2} x_{\pi, t}\right]+A_{2} \beta_{3} x_{\pi, t}\right)\right) \\
& -\theta\left(A_{0}+A_{1} x_{c, t}+A_{2} x_{\pi, t}\right)+\theta\left(\mu_{c}+x_{c, t}\right)-\lambda\left(\mu_{\pi}+x_{\pi, t}\right) \\
& =\theta \ln (\delta)-\frac{\theta}{\psi} \mu_{c}+\theta\left(k_{c, 0}+k_{c, 1} A_{0}-A_{0}+\mu_{c}\right)-\lambda \mu_{\pi} \\
& +x_{c, t}\left(-\frac{\theta}{\psi}+\theta k_{c, 1} A_{1} \beta_{1}-\theta A_{1}+\theta\right) \\
& +x_{\pi, t}\left(\theta k_{c, 1}\left(A_{1} \beta_{2}+A_{2} \beta_{3}\right)-\theta A_{2}-\lambda\right) .
\end{aligned}
$$

Likewise, the conditional variance is given by:

$$
\begin{aligned}
& \operatorname{Var}_{t}\left[\theta \ln (\delta)-\frac{\theta}{\psi} \Delta c_{t+1}+\theta r_{c, t+1}-\lambda \pi_{t+1}\right] \\
& =\operatorname{Var}_{t}\left(-\frac{\theta}{\psi} \sigma_{c} \eta_{c, t+1}+\theta k_{c, 1}\left(A_{1} \sigma_{x c} \varepsilon_{c, t+1}+A_{2} \sigma_{x \pi} \varepsilon_{\pi, t+1}\right)+\theta \sigma_{c} \eta_{c, t+1}-\lambda \sigma_{\pi} \eta_{\pi, t+1}\right) \\
& =\left(\theta-\frac{\theta}{\psi}\right)^{2} \sigma_{c}^{2}+\left(\theta k_{c, 1} A_{1} \sigma_{x c}\right)^{2}+\left(\theta k_{c, 1} A_{2} \sigma_{x \pi}\right)^{2}+\left(\lambda \sigma_{\pi}\right)^{2}
\end{aligned}
$$

Solving for $A_{0}$ yields: 


$$
\begin{aligned}
0 & =\theta \ln (\delta)-\frac{\theta}{\psi} \mu_{c}+\theta\left(k_{c, 0}+k_{c, 1} A_{0}-A_{0}+\mu_{c}\right)-\lambda \mu_{\pi} \\
& +\frac{1}{2}\left\{\left(\theta-\frac{\theta}{\psi}\right)^{2} \sigma_{c}^{2}+\left(\theta k_{c, 1} A_{1} \sigma_{x c}\right)^{2}+\left(\theta k_{c, 1} A_{2} \sigma_{x \pi}\right)^{2}+\left(\lambda \sigma_{\pi}\right)^{2}\right\} \\
& \mathbb{I} \\
A_{0} & =\frac{\theta \ln (\delta)-\frac{\theta}{\psi} \mu_{c}+\theta\left(k_{c, 0}+\mu_{c}\right)-\lambda \mu_{\pi}+\frac{1}{2}\left\{\left(\theta-\frac{\theta}{\psi}\right)^{2} \sigma_{c}^{2}+\left(\theta k_{c, 1} A_{1} \sigma_{x c}\right)^{2}+\left(\theta k_{c, 1} A_{2} \sigma_{x \pi}\right)^{2}+\left(\lambda \sigma_{\pi}\right)^{2}\right\}}{\theta\left(1-k_{c, 1}\right)}
\end{aligned}
$$

Solving for $A_{1}$ yields:

$$
\begin{aligned}
0 & =-\frac{\theta}{\psi}+\theta k_{c, 1} A_{1} \beta_{1}-\theta A_{1}+\theta \\
& \mathbb{1} \\
A_{1} & =\frac{1-\frac{1}{\psi}}{1-k_{c, 1} \beta_{1}}
\end{aligned}
$$

Solving for $A_{2}$ yields:

$$
\begin{aligned}
0 & =\theta k_{c, 1}\left(A_{1} \beta_{2}+A_{2} \beta_{3}\right)-\theta A_{2}-\lambda \\
& \mathbb{1} \\
A_{2} & =\frac{k_{c, 1} A_{1} \beta_{2}-\frac{\lambda}{\theta}}{1-k_{c, 1} \beta_{3}}
\end{aligned}
$$

\section{Appendix 3. Solving for the price-dividend ratio}

With joint log-normality the Euler equation for the dividend claim (allowing for potential money illusion) can be written as:

$$
\begin{aligned}
0 & =E_{t}\left[\theta \ln (\delta)-\frac{\theta}{\psi} \Delta c_{t+1}-(1-\theta) r_{c, t+1}+r_{m, t+1}-\lambda \pi_{t+1}\right] \\
& +\frac{1}{2} \operatorname{Var}_{t}\left[\theta \ln (\delta)-\frac{\theta}{\psi} \Delta c_{t+1}-(1-\theta) r_{c, t+1}+r_{m, t+1}-\lambda \pi_{t+1}\right] .
\end{aligned}
$$

Inserting the data-generating processes for the state variables (8)-(10), (12), (17), the log-linearized return relations (6)-(7), the log-price consumption ratio (13), and the log- 
price-dividend ratio (14), the conditional mean is given by:

$$
\begin{aligned}
& E_{t}\left[\theta \ln (\delta)-\frac{\theta}{\psi} \Delta c_{t+1}-(1-\theta) r_{c, t+1}+r_{m, t+1}-\lambda \pi_{t+1}\right] \\
& =\theta \ln (\delta)-\frac{\theta}{\psi}\left(\mu_{c}+x_{c, t}\right)-(1-\theta)\left(k_{c, 0}+k_{c, 1}\left(A_{0}+A_{1}\left[\beta_{1} x_{c, t}+\beta_{2} x_{\pi, t}\right]+A_{2} \beta_{3} x_{\pi, t}\right)\right) \\
& +(1-\theta)\left(A_{0}+A_{1} x_{c, t}+A_{2} x_{\pi, t}\right)-(1-\theta)\left(\mu_{c}+x_{c, t}\right) \\
& +\left(k_{d, 0}+k_{d, 1}\left(B_{0}+B_{1}\left[\beta_{1} x_{c, t}+\beta_{2} x_{\pi, t}\right]+B_{2} \beta_{3} x_{\pi, t}\right)\right)-\left(B_{0}+B_{1} x_{c, t}+B_{2} x_{\pi, t}\right) \\
& +\mu_{d}+\phi x_{c, t}-\lambda\left(\mu_{\pi}+x_{\pi, t}\right) \\
& =\theta \ln (\delta)-\frac{\theta}{\psi} \mu_{c}-(1-\theta)\left(k_{c, 0}+k_{c, 1} A_{0}-A_{0}+\mu_{c}\right)+k_{d, 0}+k_{d, 1} B_{0}-B_{0}+\mu_{d}-\lambda \mu_{\pi} \\
& +x_{c, t}\left(-\frac{\theta}{\psi}-(1-\theta)\left(k_{c, 1} A_{1} \beta_{1}-A_{1}+1\right)+k_{d, 1} B_{1} \beta_{1}-B_{1}+\phi\right) \\
& +x_{\pi, t}\left(-(1-\theta)\left(k_{c, 1}\left(A_{1} \beta_{2}+A_{2} \beta_{3}\right)-A_{2}\right)+k_{d, 1}\left(B_{1} \beta_{2}+B_{2} \beta_{3}\right)-B_{2}-\lambda\right)
\end{aligned}
$$

Likewise, the conditional variance is given by:

$$
\begin{aligned}
& \operatorname{Var}_{t}\left[\theta \ln (\delta)-\frac{\theta}{\psi} \Delta c_{t+1}-(1-\theta) r_{c, t+1}+r_{m, t+1}-\lambda \pi_{t+1}\right] \\
& =\operatorname{Var}_{t}\left[-\frac{\theta}{\psi} \sigma_{c} \eta_{c, t+1}-(1-\theta) k_{c, 1}\left(A_{1} \sigma_{x c} \varepsilon_{c, t+1}+A_{2} \sigma_{x \pi} \varepsilon_{\pi, t+1}\right)-(1-\theta) \sigma_{c} \eta_{c, t+1}\right. \\
& \left.+k_{d, 1}\left(B_{1} \sigma_{x c} \varepsilon_{c, t+1}+B_{2} \sigma_{x \pi} \varepsilon_{\pi, t+1}\right)+\sigma_{d} \eta_{d, t+1}-\lambda \sigma_{\pi} \eta_{\pi, t+1}\right] \\
& =\left(\theta-1-\frac{\theta}{\psi}\right)^{2} \sigma_{c}^{2}+\left((1-\theta) k_{c, 1} A_{1} \sigma_{x c}\right)^{2}+\left((1-\theta) k_{c, 1} A_{2} \sigma_{x \pi}\right)^{2}+\left(k_{d, 1} B_{1} \sigma_{x c}\right)^{2} \\
& +\left(k_{d, 1} B_{2} \sigma_{x \pi}\right)^{2}+\sigma_{d}^{2}+\left(\lambda \sigma_{\pi}\right)^{2}
\end{aligned}
$$

Solving for $B_{0}$ yields:

$$
\begin{aligned}
0 & =\theta \ln (\delta)-\frac{\theta}{\psi} \mu_{c}-(1-\theta)\left(k_{c, 0}+k_{c, 1} A_{0}-A_{0}+\mu_{c}\right)+k_{d, 0}+k_{d, 1} B_{0}-B_{0}+\mu_{d}-\lambda \mu_{\pi} \\
& +\frac{1}{2}\left\{\left(\theta-1-\frac{\theta}{\psi}\right)^{2} \sigma_{c}^{2}+\left[\left((1-\theta) k_{c, 1} A_{1}\right)^{2}+\left(k_{d, 1} B_{1}\right)^{2}\right] \sigma_{x c}^{2}\right\} \\
& \left.+\frac{1}{2}\left\{\left[(1-\theta) k_{c, 1} A_{2}\right)^{2}+\left(k_{d, 1} B_{2}\right)^{2}\right] \sigma_{x \pi}^{2}+\sigma_{d}^{2}+\lambda^{2} \sigma_{\pi}^{2}\right\} \\
& \mathbb{1}
\end{aligned}
$$




$$
\begin{aligned}
B_{0} & =\frac{\theta \ln (\delta)-\frac{\theta}{\psi} \mu_{c}-(1-\theta)\left(k_{c, 0}+k_{c, 1} A_{0}-A_{0}+\mu_{c}\right)+k_{d, 0}+\mu_{d}-\lambda \mu_{\pi}}{1-k_{d, 1}} \\
& +\frac{\frac{1}{2}\left\{\left(\theta-1-\frac{\theta}{\psi}\right)^{2} \sigma_{c}^{2}+\left[\left((1-\theta) k_{c, 1} A_{1}\right)^{2}+\left(k_{d, 1} B_{1}\right)^{2}\right] \sigma_{x c}^{2}\right\}}{1-k_{d, 1}} \\
& +\frac{\frac{1}{2}\left\{\left[\left((1-\theta) k_{c, 1} A_{2}\right)^{2}+\left(k_{d, 1} B_{2}\right)^{2}\right] \sigma_{x \pi}^{2}+\sigma_{d}^{2}+\lambda^{2} \sigma_{\pi}^{2}\right\}}{1-k_{d, 1}}
\end{aligned}
$$

Solving for $B_{1}$ yields (when inserting for $A_{1}$ ):

$$
\begin{aligned}
0 & =-\frac{\theta}{\psi}-(1-\theta)\left(k_{c, 1} A_{1} \beta_{1}-A_{1}+1\right)+k_{d, 1} B_{1} \beta_{1}-B_{1}+\phi \\
& \mathbb{} \\
B_{1} & =\frac{\phi-\frac{1}{\psi}}{1-k_{d, 1} \beta_{1}}
\end{aligned}
$$

Solving for $B_{2}$ yields (when inserting for $A_{2}$ ):

$$
\begin{aligned}
0 & =-(1-\theta)\left(k_{c, 1}\left(A_{1} \beta_{2}+A_{2} \beta_{3}\right)-A_{2}\right)+k_{d, 1}\left(B_{1} \beta_{2}+B_{2} \beta_{3}\right)-B_{2}-\lambda \\
& \mathbb{1} \\
B_{2} & =\frac{k_{d, 1} B_{1} \beta_{2}-\frac{\lambda}{\theta}}{1-k_{d, 1} \beta_{3}}
\end{aligned}
$$

\section{Appendix 4: Solving for the term structure of real interest rates}

With joint log-normality the Euler equation for zero coupon bonds (allowing for potential money illusion) can be written as:

$$
p_{t}^{(n)}=E_{t}\left(p_{t+1}^{(n-1)}+\widehat{m}_{t+1}\right)+\frac{1}{2} \operatorname{Var}_{t}\left(p_{t+1}^{(n-1)}+\widehat{m}_{t+1}\right),
$$

where $\widehat{m}_{t+1}$ is given by (5).

Inserting the data-generating processes for the state variables (8)-(10), (12), (17), the log-linearized return relation (6), the conjectured log-price consumption ratio (13), and 
the conjectured bond price (20), the conditional mean is given by:

$$
\begin{aligned}
& E_{t}\left[D_{0}^{(n-1)}+D_{1}^{(n-1)} x_{c, t+1}+D_{2}^{(n-1)} x_{\pi, t+1}+\theta \ln (\delta)-\frac{\theta}{\psi} \Delta c_{t+1}-(1-\theta) r_{c, t+1}-\lambda \pi_{t+1}\right] \\
& =D_{0}^{(n-1)}+D_{1}^{(n-1)}\left[\beta_{1} x_{c, t}+\beta_{2} x_{\pi, t}\right]+D_{2}^{(n-1)} \beta_{3} x_{\pi, t}+\theta \ln (\delta)-\frac{\theta}{\psi}\left(\mu_{c}+x_{c, t}\right) \\
& -(1-\theta)\left(k_{c, 0}+k_{c, 1}\left(A_{0}+A_{1}\left[\beta_{1} x_{c, t}+\beta_{2} x_{\pi, t}\right]+A_{2} \beta_{3} x_{\pi, t}\right)\right) \\
& +(1-\theta)\left(A_{0}+A_{1} x_{c, t}+A_{2} x_{\pi, t}\right)-(1-\theta)\left(\mu_{c}+x_{c, t}\right)-\lambda\left(\mu_{\pi}+x_{\pi, t}\right) \\
& =D_{0}^{(n-1)}+\theta \ln (\delta)-\frac{\theta}{\psi} \mu_{c}-(1-\theta)\left(k_{c, 0}+k_{c, 1} A_{0}-A_{0}+\mu_{c}\right)-\lambda \mu_{\pi} \\
& +x_{c, t}\left(D_{1}^{(n-1)} \beta_{1}-\frac{\theta}{\psi}-(1-\theta) k_{c, 1} A_{1} \beta_{1}+(1-\theta) A_{1}-(1-\theta)\right) \\
& +x_{\pi, t}\left(D_{1}^{(n-1)} \beta_{2}+D_{2}^{(n-1)} \beta_{3}-(1-\theta) k_{c, 1}\left(A_{1} \beta_{2}+A_{2} \beta_{3}\right)+(1-\theta) A_{2}-\lambda\right) .
\end{aligned}
$$

Likewise, the conditional variance is given by:

$$
\begin{aligned}
& \operatorname{Var}_{t}\left[D_{0}^{(n-1)}+D_{1}^{(n-1)} x_{c, t+1}+D_{2}^{(n-1)} x_{\pi, t+1}+\theta \ln (\delta)-\frac{\theta}{\psi} \Delta c_{t+1}-(1-\theta) r_{c, t+1}-\lambda \pi_{t+1}\right] \\
& =\operatorname{Var}_{t}\left(D_{1}^{(n-1)} \sigma_{x c} \varepsilon_{c, t+1}+D_{2}^{(n-1)} \sigma_{x \pi} \varepsilon_{\pi, t+1}-\frac{\theta}{\psi} \sigma_{c} \eta_{c, t+1}-\right. \\
& \left.(1-\theta) k_{c, 1}\left(A_{1} \sigma_{x c} \varepsilon_{c, t+1}+A_{2} \sigma_{x \pi} \varepsilon_{\pi, t+1}\right)-(1-\theta) \sigma_{c} \eta_{c, t+1}-\lambda \sigma_{\pi} \eta_{\pi, t+1}\right) \\
& =\left(D_{1}^{(n-1)} \sigma_{x c}\right)^{2}+\left(D_{2}^{(n-1)} \sigma_{x \pi}\right)^{2}+\left(\theta-1-\frac{\theta}{\psi}\right)^{2} \sigma_{c}^{2}+\left((1-\theta) k_{c, 1} A_{1} \sigma_{x c}\right)^{2} \\
& +\left((1-\theta) k_{c, 1} A_{2} \sigma_{x \pi}\right)^{2}+\left(\lambda \sigma_{\pi}\right)^{2} .
\end{aligned}
$$

Solving for $D_{0}^{(n)}$ yields:

$$
\begin{aligned}
D_{0}^{(n)} & =D_{0}^{(n-1)}+\theta \ln (\delta)-\frac{\theta}{\psi} \mu_{c}-(1-\theta)\left(k_{c, 0}+k_{c, 1} A_{0}-A_{0}+\mu_{c}\right)-\lambda \mu_{\pi} \\
& +\frac{1}{2}\left[\left(D_{1}^{(n-1)} \sigma_{x c}\right)^{2}+\left(D_{2}^{(n-1)} \sigma_{x \pi}\right)^{2}+\left(\theta-1-\frac{\theta}{\psi}\right)^{2} \sigma_{c}^{2}\right] \\
& +\frac{1}{2}\left[\left((1-\theta) k_{c, 1} A_{1} \sigma_{x c}\right)^{2}+\left((1-\theta) k_{c, 1} A_{2} \sigma_{x \pi}\right)^{2}+\left(\lambda \sigma_{\pi}\right)^{2}\right]
\end{aligned}
$$


Solving for $D_{1}^{(n)}$ yields:

$$
\begin{aligned}
D_{1}^{(n)} & =D_{1}^{(n-1)} \beta_{1}-\frac{\theta}{\psi}-(1-\theta) k_{c, 1} A_{1} \beta_{1}+(1-\theta) A_{1}-(1-\theta) \\
& =D_{1}^{(n-1)} \beta_{1}-\frac{1}{\psi} \\
& =-\frac{1}{\psi} \cdot \frac{1-\beta_{1}^{n}}{1-\beta_{1}}
\end{aligned}
$$

Solving for $D_{2}^{(n)}$ yields:

$$
\begin{aligned}
D_{2}^{(n)} & =D_{1}^{(n-1)} \beta_{2}+D_{2}^{(n-1)} \beta_{3}-(1-\theta) k_{c, 1}\left(A_{1} \beta_{2}+A_{2} \beta_{3}\right)+(1-\theta) A_{2}-\lambda \\
& =D_{1}^{(n-1)} \beta_{2}+D_{2}^{(n-1)} \beta_{3}-\frac{\lambda}{\theta} \\
& =\beta_{2}\left(D_{1}^{(n-1)}+\beta_{3} D_{1}^{(n-2)}+\beta_{3}^{2} D_{1}^{(n-3)}+\ldots+\beta_{3}^{n-2} D_{1}^{(1)}\right)-\frac{\lambda}{\theta} \cdot \frac{1-\beta_{3}^{n+1}}{1-\beta_{3}}
\end{aligned}
$$




\section{References}

[1] Acker, D., and Duck, N.W. (2013). Inflation illusion and the US dividend yield: Some further evidence. Journal of International Money and Finance 33, 235-254.

[2] Ang, A., and Bekaert, G. (2007): Stock return predictability: Is it there? Review of Financial Studies 20, 651-707.

[3] Ang, A., Bekaert, G., and Wei, M. (2008). The term structure of real rates and expected inflation. Journal of Finance 63, 797-849.

[4] Asness, C. (2000). Stocks versus bonds: Explaining the equity risk premium. Financial Analysts Journal, March/April 2000, 96-113.

[5] Asness, C. (2003). Fight the Fed model: The relationship between future returns and stock and bond market yields. Journal of Portfolio Management, Fall 2003, 11-24.

[6] Attanasio, O.P. and Vissing-Jorgensen, A. (2003). Stock market participation, intertemporal substitution and risk aversion. American Economic Review 93, 383-391.

[7] Attanasio, O.P. and Weber, G. (1993). Consumption growth, the interest rate and aggregation. Review of Economic Studies 60, 631-649.

[8] Bansal, R. and Shaliastovich, I. (2013). A long-run risk explanation of predictability puzzles in bond and currency markets. Review of Financial Studies 26, 1-33.

[9] Bansal, R. and Yaron, A. (2004). Risks for the long run: A potential resolution of asset pricing puzzles. Journal of Finance 59, 1481-1509.

[10] Banz, R.W. (1981). The relationship between return and market value of common stocks. Journal of Financial Economics 9, 3-18.

[11] Basak, S. and Yan, H. (2010). Equilibrium asset prices and investor behaviour in the presence of money illusion. Review of Economic Studies 77, 914-936.

[12] Beeler, J. and Campbell, J.Y. (2012). The long-run risks model and aggregate asset prices: An empirical assessment. Critical Finance Review 1, 141-182.

[13] Bekaert, G., and Engstrom, E. (2010). Inflation and the stock market: Understanding the "Fed model". Journal of Monetary Economics 57, 278-294.

[14] Brunnermeier, M.K., and Julliard, C. (2008). Money illusion and housing frenzies. Review of Financial Studies 21, 135-180. 
[15] Bruno, M., and Sachs, J. (1985). Economics of Worldwide Stagflation. Basil Blackwell, Oxford.

[16] Campbell, J.Y., and Shiller, R.J. (1988). The dividend-price ratio and expectations of future dividends and discount factors. Review of Financial Studies 1, 195-228.

[17] Campbell, J.Y., and Vuolteenaho, T. (2004). Inflation illusion and stock prices. American Economic Review, Papers and Proceedings 94, 19-23.

[18] Chen, C.R., Lung, P.P., and Wang, F.A. (2009). Stock market mispricing: Money illusion or resale option? Journal of Financial and Quantitative Analysis 44, 11251147.

[19] Chen, X., Favilukis, J., and Ludvigson, S.C. (2013). An estimation of economic models with recursive preferences. Quantitative Economics 4, 39-83.

[20] Cochrane, J.H. (2008). The dog that did not bark. A defense of return predictability. Review of Financial Studies 21, 1533-1575.

[21] Cohen, R.B., Polk, C., and Vuolteenaho, T. (2005). Money illusion in the stock market: The Modigliani-Cohn hypothesis. Quarterly Journal of Economics 120, 639-668.

[22] Engsted, T., and Pedersen, T.Q. (2010). The dividend-price ratio does predict dividend growth: International evidence. Journal of Empirical Finance 17, 585-605.

[23] Engsted, T., Pedersen, T.Q., and Tanggaard, C. (2012). The log-linear return approximation, bubbles, and predictability. Journal of Financial and Quantitative Analysis 47, 643-665.

[24] Epstein, L., Farhi, E., and Strzalecki, T. (2014). How much would you pay to resolve long-run risk? American Economic Review 104, 2680-2697.

[25] Epstein, L. and Zin, S. (1989). Substitution, risk aversion, and the temporal behavior of consumption and asset returns: A theoretical framework. Econometrica 57, 937968.

[26] Fama, E.F. (1975). Short-term interest rates as predictors of inflation. American Economic Review 65, 269-282.

[27] Fama, E.F. (1981). Stock returns, real activity, inflation and money. American Economic Review 71, 545-565. 
[28] Fama, E.F. and Schwert, G.W. (1977). Asset returns and inflation. Journal of Financial Economics 5, 115-146.

[29] Fisher, I. (1928). The Money Illusion. Adelphi, New York.

[30] Friedman, M. (1968). The role of monetary policy. American Economic Review 57, $1-17$.

[31] Friedman, M. (1977). Nobel lecture: Inflation and unemployment. Journal of Political Economy 85, 451-472.

[32] Hall, R.E. (1988). Intertemporal substitution in consumption. Journal of Political Economy 96, 339-357.

[33] Hodrick, R.J. (1992). Dividend yields and expected stock returns: Alternative procedures for inference and measurement. Review of Financial Studies 5, 357-386.

[34] Lee, B.S. (2010). Stock returns and inflation revisited: An evaluation of the inflation illusion hypothesis. Journal of Banking and Finance 34, 1257-1273.

[35] Modigliani, F., and Cohn, R.A. (1979). Inflation, rational valuation and the market. Financial Analysts Journal, March/April 1979, 24-44.

[36] Newey, W.K., and West, K.D. (1987). A simple positive semi-definite, heteroscedasticity and autocorrelation consistent covariance matrix. Econometrica 55, 703-708.

[37] Phelps, E.S. (1968). Money, wage dynamics and labor market equilibrium. Journal of Political Economy 76, 678-711.

[38] Ritter, J.R., and Warr, R.S. (2002). The decline of inflation and the bull market of 1982-1999. Journal of Financial and Quantitative Analysis 37, 29-61.

[39] Schwert G.W. (2003). Anomalies and market efficiency Handbook of the Economics of Finance, G.M. Constantinides, M. Harris and R.M. Stulz (Eds.), 939-974.

[40] Sharpe, S.A. (2002). Reexamining stock valuation and inflation: The implications of analysts' earnings forecasts. Review of Economics and Statistics 84, 632-648.

[41] Thimme, J. (2017). Intertemporal substitution in consumption: A literature review. Journal of Economic Surveys 31, 226-257.

[42] Wei, C. (2010). Inflation and stock prices: No illusion. Journal of Money, Credit, and Banking 42, 325-345. 
[43] Weil, P. (1989). The equity premium puzzle and the risk-free rate puzzle. Journal of Monetary Economics 24, 401-421. 
Figure 1. The price-dividend ratio and the subsequent 20-year inflation rate.

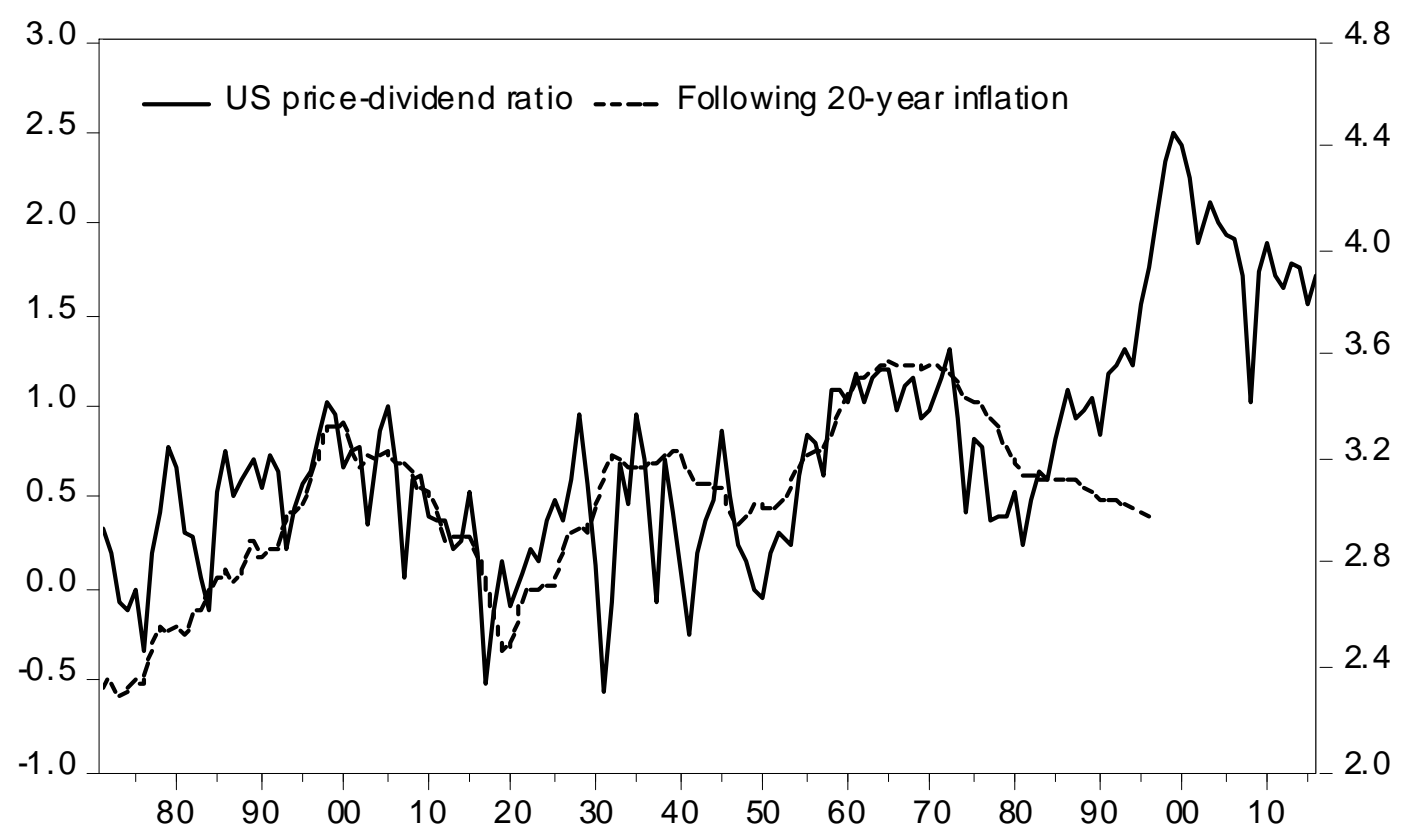

Note: The figure shows the log price-dividend ratio (solid line, right axis) and the subsequent 20-year long inflation rate (dashed line, left axis) over the period 1871-2016. For inflation the last observation is in 1996 which gives the inflation rate from 1996 to 2016. 
Table 1. Multiperiod inflation predictability by the price-dividend ratio.

\begin{tabular}{|c|c|c|c|c|c|}
\hline & \multicolumn{5}{|c|}{$k$ (years) } \\
\hline & 1 & 5 & 10 & 15 & 20 \\
\hline \multicolumn{6}{|l|}{$1871-2016$} \\
\hline$\widehat{\beta}_{\pi, k}$ & 0.018 & 0.061 & 0.175 & 0.372 & 0.808 \\
\hline$t$-stat & 1.134 & 1.423 & 2.876 & 4.640 & 8.248 \\
\hline$P_{B}$ & 0.074 & 0.133 & 0.043 & 0.005 & 0.000 \\
\hline$R^{2}$ & 0.017 & 0.020 & 0.060 & 0.131 & 0.298 \\
\hline \multicolumn{6}{|l|}{$1871-1976$} \\
\hline$\widehat{\beta}_{\pi, k}$ & 0.049 & 0.151 & 0.445 & 0.814 & 1.087 \\
\hline t-stat & 1.464 & 1.655 & 3.734 & 5.151 & 6.675 \\
\hline$P_{B}$ & 0.017 & 0.047 & 0.001 & 0.000 & 0.000 \\
\hline$R^{2}$ & 0.046 & 0.046 & 0.152 & 0.299 & 0.415 \\
\hline \multicolumn{6}{|l|}{$1977-2016$} \\
\hline$\widehat{\beta}_{\pi, k}$ & -0.037 & -0.154 & & & \\
\hline t-stat & -2.493 & -7.416 & & & \\
\hline$P_{B}$ & 0.001 & 0.001 & & & \\
\hline$R^{2}$ & 0.372 & 0.365 & & & \\
\hline
\end{tabular}

Note: $\mathrm{k}$ denotes the horizon in the multiperiod regression. t-statistics for $\mathrm{k}=1$ are based on Newey and West (1987) heteroskedasticity and autocorrelation robust standard errors, while for $\mathrm{k}>1$ they are based on Hodrick (1992) standard errors. $\mathrm{P}_{\mathrm{B}}$ denotes the bootstrapped p-value computed under the null hypothesis of no predictability. For the sample period 1871-1976, the last observation for the pricedividend ratio is 1976 , i.e. for $\mathrm{k}=1$ inflation is measured from $1871-1977$, for $\mathrm{k}=5$ inflation is measured from 1871-1981 etc. 
Table 2. Multiperiod return and dividend growth predictability by the price-dividend ratio, 1871-1976.

\begin{tabular}{cccccc}
\hline \multicolumn{7}{c}{$k$ (years) } \\
\cline { 2 - 6 } & 1 & 5 & 10 & 15 & 20 \\
\hline
\end{tabular}

Nominal returns

$\begin{array}{crrrrr}\widehat{\beta}_{n, k} & -0.067 & -0.475 & -0.464 & -0.459 & -0.129 \\ t \text {-stat } & -1.333 & -2.248 & -1.301 & -0.864 & -0.221 \\ P_{B} & 0.216 & 0.045 & 0.170 & 0.280 & 0.641 \\ R^{2} & 0.012 & 0.150 & 0.100 & 0.065 & 0.004\end{array}$

Real returns

$\begin{array}{crrrrr}\widehat{\beta}_{r, k} & -0.116 & -0.625 & -0.909 & -1.273 & -1.216 \\ t \text {-stat } & -2.160 & -2.736 & -2.298 & -2.269 & -2.065 \\ P_{B} & 0.072 & 0.009 & 0.008 & 0.002 & 0.011 \\ R^{2} & 0.036 & 0.247 & 0.300 & 0.441 & 0.402\end{array}$

Nominal dividend growth

$\begin{array}{cccccc}\widehat{\beta}_{n, k} & 0.255 & 0.347 & 0.390 & 0.800 & 0.939 \\ t \text {-stat } & 3.643 & 2.156 & 1.985 & 2.646 & 2.479 \\ P_{B} & 0.000 & 0.020 & 0.073 & 0.007 & 0.006 \\ R^{2} & 0.284 & 0.098 & 0.098 & 0.232 & 0.275\end{array}$

Real dividend growth

$\begin{array}{crrrrr}\widehat{\beta}_{r, k} & 0.206 & 0.197 & -0.055 & -0.014 & -0.147 \\ \text { t-stat } & 2.987 & 1.335 & -0.276 & -0.051 & -0.426 \\ P_{B} & 0.000 & 0.137 & 0.327 & 0.370 & 0.235 \\ R^{2} & 0.203 & 0.044 & 0.003 & 0.000 & 0.020\end{array}$

Note: See notes to Table 1. 
Table 3. Survey-based measures of expected inflation and expected consumption growth.

\begin{tabular}{|c|c|c|c|c|c|c|c|c|}
\hline \multirow{3}{*}{ A: Equation (11 } & \multicolumn{4}{|c|}{ Livingston Survey } & \multicolumn{4}{|c|}{ Survey of Prof. Forecasters } \\
\hline & \multirow[t]{2}{*}{$\beta_{1}$} & \multirow[t]{2}{*}{$\beta_{2}$} & \multirow[t]{2}{*}{$\beta_{3}$} & \multirow[t]{2}{*}{$R^{2}$} & \multirow[t]{2}{*}{$\beta_{1}$} & \multirow[t]{2}{*}{$\beta_{2}$} & \multirow[t]{2}{*}{$\beta_{3}$} & \multirow[t]{2}{*}{$R^{2}$} \\
\hline & & & & & & & & \\
\hline Up to 1976 & 0.639 & & & 0.399 & 0.859 & & & 0.724 \\
\hline & $(5.65)$ & & & {$[0.013]$} & $(8.86)$ & & & {$[0.008]$} \\
\hline $1977-2016$ & 0.549 & & & 0.313 & 0.865 & & & 0.777 \\
\hline & $(5.96)$ & & & {$[0.010]$} & $(23.46)$ & & & {$[0.004]$} \\
\hline \multicolumn{9}{|c|}{ B: Equation (12) } \\
\hline \multirow[t]{2}{*}{ Up to 1976} & & & 0.979 & 0.991 & & & 0.900 & 0.820 \\
\hline & & & $(22.18)$ & {$[0.006]$} & & & $(11.68)$ & {$[0.006]$} \\
\hline \multirow[t]{2}{*}{$1977-2016$} & & & 0.961 & 0.929 & & & 0.985 & 0.975 \\
\hline & & & $(31.93)$ & {$[0.005]$} & & & $(78.80)$ & {$[0.003]$} \\
\hline \multicolumn{9}{|c|}{ C: Equation (17) } \\
\hline \multirow[t]{2}{*}{ Up to 1976} & 0.584 & 0.137 & & 0.423 & 0.847 & 0.151 & & 0.743 \\
\hline & $(4.92)$ & $(1.40)$ & & {$[0.013]$} & $(8.89)$ & $(1.49)$ & & {$[0.008]$} \\
\hline \multirow[t]{2}{*}{$1977-2016$} & 0.503 & -0.095 & & 0.334 & 0.858 & -0.016 & & 0.778 \\
\hline & $(5.23)$ & $(-1.56)$ & & {$[0.010]$} & $(22.84)$ & $(-0.93)$ & & {$[0.004]$} \\
\hline
\end{tabular}

Note: Data based on the Livingston Survey cover the period 1951-2016 on a semi-annual frequency. Data based on Survey of Professional Forecasters cover the period 1968-2016 on a quarterly frequency. Numbers in parentheses are t-statistics and numbers in brackets are regression standard errors. Testing for a structural break in $\beta_{2}$ in 1976-1977 a Chow breakpoint test based on equation (17) yields a Wald test statistic of 4.66 (p-value equal to 0.03 ) using Livingston Survey data, and 6.72 (p-value equal to 0.01) using data from the Survey of Professional Forecasters. 
Table 4. Inflation predictability by the price-dividend ratio under money illusion.

\begin{tabular}{cccccc}
\hline & \multicolumn{5}{c}{$k$ (years) } \\
\cline { 2 - 6 } & 1 & 5 & 10 & 15 & 20 \\
\hline $\mathrm{A}: \lambda=0, \psi=2, \gamma=2$ & & & & & \\
\hline$\widehat{\beta}_{\pi, k}$ & & & & & \\
$t$-stat & 0.001 & 0.006 & 0.000 & 0.004 & 0.004 \\
$R^{2}$ & 0.006 & 0.021 & 0.001 & 0.009 & 0.009 \\
& 0.013 & 0.024 & 0.026 & 0.027 & 0.026
\end{tabular}

B: $\lambda=1, \psi=0.5, \gamma=2$

$\begin{array}{lrrrrr}\widehat{\beta}_{\pi, k} & -0.141 & -0.533 & -0.768 & -0.847 & -0.853 \\ t \text {-stat } & -5.872 & -3.859 & -3.402 & -2.952 & -2.560 \\ R^{2} & 0.234 & 0.396 & 0.321 & 0.240 & 0.184\end{array}$

$\mathrm{C}: \lambda=1, \psi=2, \gamma=2$

$\begin{array}{cccccc}\widehat{\beta}_{\pi, k} & 0.178 & 0.680 & 0.988 & 1.096 & 1.115 \\ \text { t-stat } & 4.378 & 3.444 & 3.099 & 2.713 & 2.378 \\ R^{2} & 0.155 & 0.265 & 0.218 & 0.165 & 0.131\end{array}$

Note: $\mathrm{k}$ denotes the horizon in the multiperiod regression. t-statistics for $\mathrm{k}=1$ are based on Newey and West (1987) heteroskedasticity and autocorrelation robust standard errors, while for $\mathrm{k}>1$ they are based on Hodrick (1992) standard errors. The reported numbers are averages across 10,000 simulations each of length $105+\mathrm{k}$ matching the length of the data used in Tables 1 and 2 for the sample period 18711976. The data-generating parameters besides those given in the table are $\delta=0.93, \mu_{c}=0.020$, $\mu_{d}=0.012, \mu_{\pi}=0.015, \phi=3, \beta_{1}=0.50, \beta_{3}=0.90, \sigma_{c}=0.035, \sigma_{d}=0.120, \sigma_{\pi}=0.055$, $\sigma_{x c}=0.015, \sigma_{x \pi}=0.015$. 
Table 5. Descriptive statistics under money illusion.

\begin{tabular}{|c|c|c|c|c|c|c|}
\hline & \multicolumn{3}{|c|}{ Actual data } & \multicolumn{3}{|c|}{ Simulated data } \\
\hline & Mean & Std.dev. & $\mathrm{AC}(1)$ & Mean & Std.dev. & $\mathrm{AC}(1)$ \\
\hline$\pi_{t}$ & 0.015 & 0.066 & 0.282 & 0.015 & 0.063 & 0.195 \\
\hline$\Delta d_{t}$ & 0.012 & 0.132 & 0.116 & 0.012 & 0.130 & 0.066 \\
\hline$\Delta c_{t}$ & 0.020 & 0.040 & -0.103 & 0.020 & 0.039 & 0.084 \\
\hline$p d_{t}$ & 3.055 & 0.286 & 0.712 & 3.016 & 0.133 & 0.713 \\
\hline
\end{tabular}

Note: The reported descriptive statistics are given for the sample period 1871-1976 (for consumption 1890-1976) corresponding to the early sub-sample period in Table 1. For the simulation results the datagenerating parameters are given in Table 4, Panel C. The reported numbers in the simulation study are averages across 10,000 simulations each of a length matching the sample period 1871-1976. AC(1) is the first-order autocorrelation coefficient. 
Table 6. Inflation predictability by the price-dividend ratio under inflation non-neutrality.

\begin{tabular}{crr}
\hline & \multicolumn{2}{c}{$k$ (years) } \\
\cline { 2 - 3 } & \multicolumn{1}{c}{1} & \multicolumn{1}{c}{5} \\
\cline { 2 - 3 }$\widehat{\beta}_{\pi, k}$ & -0.087 & -0.292 \\
$t$-stat & -5.866 & -2.985 \\
$R^{2}$ & 0.405 & 0.426 \\
& & \\
\hline
\end{tabular}

Note: $\mathrm{k}$ denotes the horizon in the multiperiod regression. t-statistics for $\mathrm{k}=1$ are based on Newey and West (1987) heteroskedasticity and autocorrelation robust standard errors, while for $\mathrm{k}=5$ they are based on Hodrick (1992) standard errors. The reported numbers are averages across 10,000 simulations each of a length matching the length of the late sample period 1977-2016. The data-generating parameters besides those given in the table are $\delta=0.93, \mu_{c}=0.019, \mu_{d}=0.025, \mu_{\pi}=0.035, \phi=3$, $\beta_{1}=0.6, \beta_{2}=-0.15, \beta_{3}=0.95, \sigma_{c}=0.01, \sigma_{d}=0.055, \sigma_{\pi}=0.02, \sigma_{x c}=0.01$, $\sigma_{x \pi}=0.01, \gamma=2, \psi=2$. 
Table 7. Multiperiod inflation predictability by the short-term real interest rate.

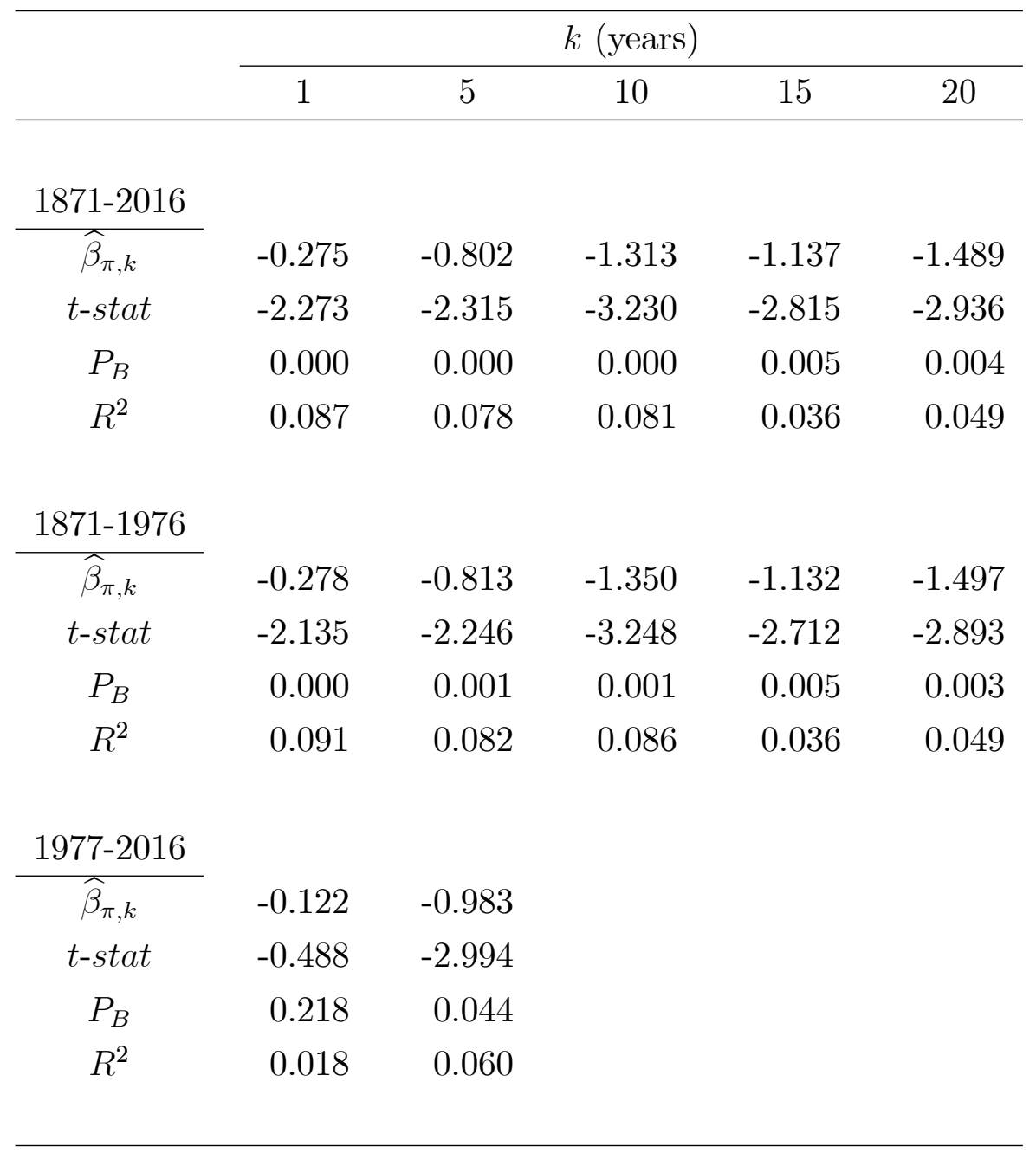

Note: See notes to Table 1. 
2018-07: Torben G. Andersen, Nicola Fusari and Viktor Todorov: The Risk Premia Embedded in Index Options

2018-08: Torben G. Andersen, Nicola Fusari and Viktor Todorov: Short-Term Market Risks Implied by Weekly Options

2018-09: Torben G. Andersen and Rasmus T. Varneskov: Consistent Inference for Predictive Regressions in Persistent VAR Economies

2018-10: Isabel Casas, Xiuping Mao and Helena Veiga: Reexamining financial and economic predictability with new estimators of realized variance and variance risk premium

2018-11: $\quad$ Yunus Emre Ergemen and Carlos Velasco: Persistence Heterogeneity Testing in Panels with Interactive Fixed Effects

2018-12: $\quad$ Hossein Asgharian, Charlotte Christiansen and Ai Jun Hou: Economic Policy Uncertainty and Long-Run Stock Market Volatility and Correlation

2018-13: Emilio Zanetti Chini: Forecasting dynamically asymmetric fluctuations of the U.S. business cycle

2018-14: Cristina Amado, Annastiina Silvennoinen and Timo Teräsvirta: Models with Multiplicative Decomposition of Conditional Variances and Correlations

2018-15: Changli He, Jian Kang, Timo Teräsvirta and Shuhua Zhang: The Shifting Seasonal Mean Autoregressive Model and Seasonality in the Central England Monthly Temperature Series, 1772-2016

2018-16: $\quad$ Ulrich Hounyo and Rasmus T. Varneskov: Inference for Local Distributions at High Sampling Frequencies: A Bootstrap Approach

2018-17: $\quad$ Søren Johansen and Morten Ørregaard Nielsen: Nonstationary cointegration in the fractionally cointegrated VAR model

2018-18: Giorgio Mirone: Cross-sectional noise reduction and more efficient estimation of Integrated Variance

2018-19: $\quad$ Kim Christensen, Martin Thyrsgaard and Bezirgen Veliyev: The realized empirical distribution function of stochastic variance with application to goodness-of-fit testing

2018-20: Ruijun Bu, Kaddour Hadri and Dennis Kristensen: Diffusion Copulas: Identification and Estimation

2018-21: Kim Christensen, Roel Oomen and Roberto Renò: The drift burst hypothesis

2018-22: $\quad$ Russell Davidson and Niels S. Grønborg: Time-varying parameters: New test tailored to applications in finance and macroeconomics

2018-23: Emilio Zanetti Chini: Forecasters' utility and forecast coherence

2018-24: $\quad$ Tom Engsted and Thomas Q. Pedersen: Disappearing money illusion 